\title{
Torque ripple reduction of a brushless DC mo- tor using Y-source converter
}

\author{
T. VenkateswaraRao* and D.V.N. Ananth** \\ * Department of EEE, K.L. University, Viziawada, India \\ ** Department of EEE, Raghu Institute of Technology, Visakhapatnam, India \\ **Corresponding Author: nagaananth@gmail.com
}

Submitted :28/03/2020

Revised : :18/07/2021

Accepted : 02/08/2021

\begin{abstract}
The brushless DC motor (BLDC) is a low cost, reliable, and efficient motor for low power applications. In general, the speed, torque, and current of the BLDC motor are controlled using a well-tuned PI controller in the inner and outer control loops. This controller will be effective in reducing the dynamic speed error but will produce large current ripples. This reference current when given to the inner control loop and controlled using hall-effect position sensing technique leads to comparatively large ripples in the torque. Because of large dynamic behavior of DC link voltage when nominal rating capacitor is used, there will be torque ripples and reduction in rotor speed from the reference current value. Hence, to mitigate these torque ripples in BLDC motor, a fast acting adjustable DC link voltage like chopper is generally used. The effective DC link voltage control with voltage boosting and controlling action is observed with Y-source converter and is compared with a Z-source converter in this paper. The Y-source converter is designed in such a way that it will effectively control the speed and also produce lesser current ripples reference. Further, the inverter topology uses a six-switch basic configuration but with a new switching strategy. The results are compared with a Z-source converter with the proposed $\mathrm{Y}$-source converter under variable load torque and variable speed cases in MATLAB/ SIMULINK environment. It is found that the torque ripples are reduced effectively without much change in the reference speed. Also, even at higher rotor speeds, the torque ripples and surges are also lesser.
\end{abstract}

Keywords: Brushless DC (BLDC) motor; Current and torque control; Torque ripples reduction, Field oriented control; Admittance source converter.

\section{INTRODUCTION}

The brushless DC motor (BLDC) is slowly replacing the most popular induction motor due to its advanced control techniques and design improvements. This is due to the fact that BLDC motors are attractive now days because of their lower cost, higher efficiency, low cost, lesser maintenance, high torque, and speed control capabilities compared to the other same class of motors (Banu Rekha et al., 2018; Toliyat et al., 2018). This motor is controlled based on the position of the rotor and is estimated by using hall sensors or using some sensor-less techniques. This BLDC motor finds applications in computers, automotive, households, industries, railway fans, house hold, and many others. The BLDC motor is used in automotive industry, solar PV-fed water pumping system, and electrical vehicle 
applications as a turbocharger, aerospace vehicle, and fuel pumps (J. Shao, 2006; R. Kumar et al., 2016; S. P. Nikam et al.,, 2012; W. Lee et al., 2018; J. Feng et al., 2018; Jianwen Shao et al., 2003).

The BLDC motor speed and torque control are extremely important for effective performance based on the application. The authors effectively demonstrated the fuzzy-PID along with model-reference adaptive control technique in the outer control loop of BLDC, which is a better speed control technique (El-Samahy et al., 2018). Such earlier speed control is done using a neurofuzzy system with weights being adjusted using BAT based metaheuristic algorithm (Premkumar, K et al., 2015). However, these two methods are very effective but are very complicated. There are various methods adopted for BLDC for higher speed operation or for very low speed operation or variable speed control (Chen, Shaohua et al., 2017; Valle, Rodolfo L et al., 2017; Potnuru, Devendra et al., 2019). The torque control is achieved using many methods, among which is one method that uses a firefly algorithm to tune the PID control parameters for better operation (Kommula et al., 2018).

The speed, torque, or power control for BLDC is obtained using famous algorithms like direct power control, direct torque control, field oriented control technique and hybrid direct torque, and field oriented control technique (de Castro et al., 2018; Lu, Youliang et al., 2018; Alouane et al., 2018; Sekhar, GT Chandra et al., 2017; Qamar, Nezar Abou et al., 2018; Gujjar, Meghana N. et al., 2017; Carey, Kellen D. et al., 2018). Among all, the hybrid technique, which uses both stationary and rotating reference frames, is found to be more feasible and attractive solution for performance improvement of BLDC. The major challenge for BLDC motor for any type of application is torque ripple reduction (Li, Xinmin et al., 2016; Sumega, Martin et al., 2019; Ransara, HK Samitha et al., 2015). The torque ripples will deteriorate the performance, efficiency, commutation, and controllability of the motor. Hence, such challenge is very crucial for most of the applications.

The BLDC motor is controlled using different control schemes to achieve rapid and required speed, torque, power, or stability. A great work is done by the authors in identifying different controllers for speed control and stability enhancement using fuzzy and many hybrid metaheuristic and intelligent control schemes (Premkumar, K et al., 2015; Premkumar, K et al., 2018). Similarly, h-infinity, Fuzzy-PSO Controller, and Adaptive sliding mode control and cuckoo method are used by these authors for lifetime and performance improvement (Krishnan, TV et al., 2017; López, Manuel García et al., 2019; Murali, S. Bala et al., 2018). Therefore, the choice of the controller other than a conventional PI controller is important for improving the motor performance. A self-driven current doubler (CD) used a new topology called phase shifted full bridge converter (PSFB) for the application of integrated magnetic (IM) with DC-to-DC converter (Cetin Sevilay, 2014). The DC-to-DC chopper converters are used for various applications like magnetic levitation, motor control, renewable energy resources like solar photovoltaic cells (Özçelik, Mehmet Ali. (2015)), wind generators (Ahmed, Mahrous et al., 2021), and fuel cells (Alharbi, Ahmed Awadh et al., 2020; and Al-Othman et al., 2016).

Different converter topologies like SEPIC and three-level neutral point converter are used for torque ripple reduction, DTC and overlap angle method, Z-source inverter, quasi-square wave inverters and Cuk, SEPIC, and Zeta converter (Viswanathan et al., 2017; Lad, Chetan K., et al., 2018; Soumi, A., et al., 2018; Jagiela, Mariusz et al., 2015; Suryoatmojo, $\mathrm{H}$ et al., 2016). The later papers deal with both the torque ripples reduction and power factor correction. Based on the converter topology and control scheme adopted, the performance like torque and speed control, torque ripples reduction, and power flow control are improved considerably. The Admittance or Y-source converter (YSC) is described for DC-DC chopper applications in Siwakoti, Yam P et al. (2015) and Wang, Yijie et al. (2018). The torque ripple reduction techniques using Z-source converter and buck-boost chopper are discussed in Xia, Kun et al. (2016) and Çelikel, Reşat et al. (2019). Grid connected inverter operation with islanding detection method used a new positive feedback variable with negative or zero sequences estimations (X Guo, 2016). 
The main benefits of the proposed Y-source inverter are as follows: 1) the neutral of the grid is directly connected to the negative terminal of the DC source or to the solar PV panel, so the leakage current is eliminated; 2) it is compact in size; 3 ) it has low cost; 4) the used DC voltage of the proposed inverter is the same as the full-bridge inverter (unlike neutral point clamped (NPC), active NPC, and half-bridge inverters); 5) it has flexible grounding configuration; 6) it has the capability of reactive power flow; and 7) it is highly efficient.

\section{Objectives}

1. To design and choose a better control strategy for the Y-source inverter for BLDC motor to have speed and torque control characteristics.

2. To develop improved topology better than famous Z-source inverter or chopper based inverter for the single or three phase grid tied system.

3. To reduce the leakage current utilizing the parasitic capacitor already present in the circuit and also the effects due to inductors, diodes, and solid-state switches.

4. To establish a bidirectional current flow to aid in charging and discharging because of energy storage devices like batteries and fuel cells.

5. Wide range of reactive power control, frequency fluctuations, and voltage disturbances.

6. Multilevel voltage levels are developed to improve the THD and voltage profile at the grid connection.

\section{Expected Output and Outcome of the proposal}

- Y-source inverter to drive the BLDC motor is planned to achieve better speed and torque control without affecting the reactive power flow, and the inverter voltage and current THD values better than earlier methods.

- The overall efficiency, current carrying capability, bidirectional current flow, and simple design are observed, and better practical feasibility among them can be observed in the real time environment.

- Better pulse control strategy for the Y-source inverter to improve the overall performance of the system and better withstanding capability with sudden change in speed and torque values.

This paper deals with Y-source converter (YSC) for speed and torque control along with torque ripple reduction. Also, with the present topology, very high load torque at high speed operation is planned. The objectives of the work are that torque surges must be low when there is a rapid change in the speed, and also, the torque ripples must be low when the speed of the rotor is adjusted at very low or higher speeds. The control scheme has to be simple and effective and can be applicable to any application like pumps, automotive, or aerospace.

\section{THE MATHEMATICAL MODELING OF BLDC MOTOR}

The modeling of BLDC motor and its dynamics is studied to understand speed and torque control characteristics and parameter dependencies. The FOC decoupling is referred to in stator flux frame with the basic relationships being represented as [J. Shao et al., 2006; El-Samahy et al., 2019). The d and q axis stator voltages of BLDC motor are given by the equations ( $1 \mathrm{a}$ and $1 \mathrm{~b}$ )

$V_{d}=R i_{d}+\rho \lambda_{d}-\omega_{r} \lambda_{q}$ 
$V_{q}=R i_{d}+\rho \lambda_{q}+\omega_{r} \lambda_{d}$

where $\mathrm{R}$ is the stator resistance, $\rho$ is the differential equation $\frac{d}{d t}$, and $\mathrm{d}$ and $\mathrm{q}$ axis flux are given by $\lambda_{d}$ and $\lambda_{q}$ with rotor angular speed given by $\omega_{r}$. The $\mathrm{d}$ and $\mathrm{q}$ axis stator flux linkages are given the equations ( $2 \mathrm{a}$ and $2 b$ ) in terms of $d$ and $q$ axis stator currents $i_{d}$ and $i_{q}$, and the mutual flux linking towards the rotor $\Psi_{R}$ and stator inductance $\mathrm{L}_{\mathrm{s}}$ is

$\lambda_{d}=L_{s} i_{d}+\psi_{R}$

$\lambda_{q}=L_{s} i_{q}$

The electromagnetic torque (EMT) (Te) in terms of $d$ and $q$ axis flux and current and also in terms of mechanical parameters is represented in equation (3).

$T_{e}=\frac{3}{2}\left(\lambda_{d} i_{q}-\lambda_{q} i_{d}\right)=\frac{3}{2} \psi_{R} i_{q}=\frac{3}{2} \frac{P}{2} \lambda_{m}=\frac{J P}{2} \dot{\omega}_{r}+\frac{3 \rho}{2} \omega_{r}+T_{l}$

$\lambda_{m}$ is the flux linking component in the permanent magnet rotor, $\mathrm{T}_{1}$ is the load torque, and $\mathrm{P}$ is the pole pairs. The $\mathrm{d}$ and $\mathrm{q}$ axis stator voltages can be derived in terms of current and $\Psi_{\mathrm{R}}$ using the equations (1a to $2 \mathrm{~b}$ ) given by (4a and $4 \mathrm{~b}$ ) equations. It can be observed that there are decoupling current parameters in the voltage, and hence, $\mathrm{d}$ or $\mathrm{q}$ axis current will effectively influence both $\mathrm{d}$ and $\mathrm{q}$ axis voltages, and effective control of this current will result in driving the BLDC motor based on the requirement.

$$
\begin{aligned}
& V_{d}=R i_{d}+L_{s} \rho i_{d}+\rho \psi_{R}-\omega_{r} L_{s} i_{q} \\
& V_{q}=R i_{q}+L_{s} \rho i_{q}+\omega_{r} \psi_{R}+\omega_{r} L_{s} i_{d}
\end{aligned}
$$

The $\Psi_{\mathrm{R}}$ flux is constant due to permanent magnet of the roar, and therefore, the rate of change of $\Psi_{\mathrm{R}}$ is zero. Under stationary rotor condition, the angular speed $\omega_{\mathrm{r}}$ is zero. Hence, the $\mathrm{d}$ and $\mathrm{q}$ axis rates of change of currents in terms of $d$ and $q$ axis voltages are shown in equation (5a):

$\frac{V_{d}-R i_{d}}{L_{s}}=\frac{d i_{d}}{d t}$ and $\frac{V_{q}-R i_{q}}{L_{s}}=\frac{d i_{q}}{d t}$

Upon solving equation (5a), the simplified $d$ and $q$ axis currents at standstill rotor condition are given by equation (5b). The $\mathrm{d}$ and $\mathrm{q}$ axes depend on the stator time constant $\tau=\frac{L_{s}}{R}$,

$i_{d}=\frac{V_{d}}{R}\left(1-e^{-\frac{R}{L_{s}} t}\right)$ and $i_{q}=\frac{V_{q}}{R}\left(1-e^{-\frac{R}{L_{s}} t}\right)$

In the same way, if the $\mathrm{d}$ and $\mathrm{q}$ axis currents and flux are controlled effectively to get the desired EMT, mostly $\mathrm{q}$ axis current will be more dominating in the field oriented control. In this regard, to achieve better control of this EMT, the q axis current control plays a vital role. 


\section{MATHEMATICAL MODELING OF Y-SOURCE CONVERTER}

The proposed Y source DC-DC chopper circuit is shown in Figure 1a, and different modes of operation are shown in Figure 1b to Figure 1e. The circuit is having source side inductor for smooth current control and initial boosting purpose. There are the second inductor (L2), three-winding inductor, capacitors (C1, C2, C3, and C4), diodes (D1 and D2), and the switch Sd for a quasi-Y-source DC-Dc chopper circuit with continuous current conduction and high voltage boosting purpose.

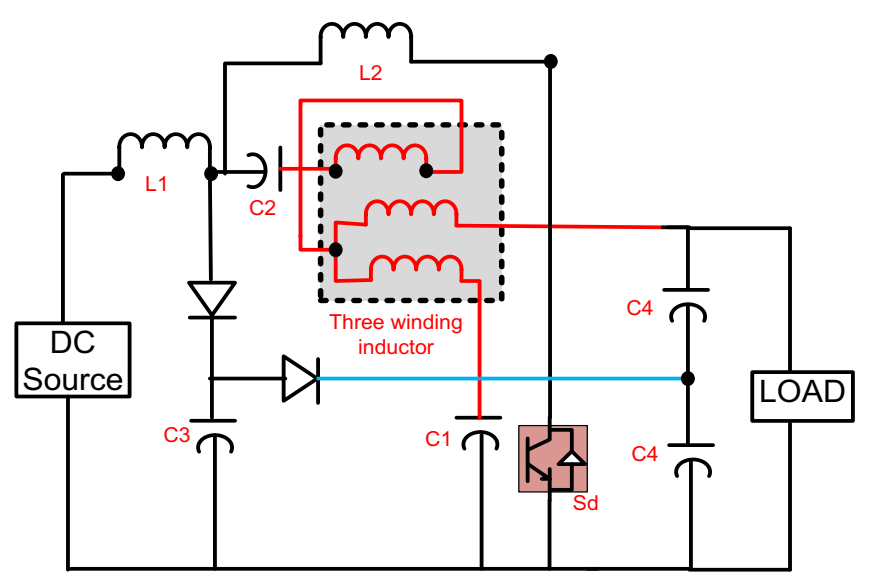

Figure 1a. Proposed Y-Source DC-DC circuit diagram.

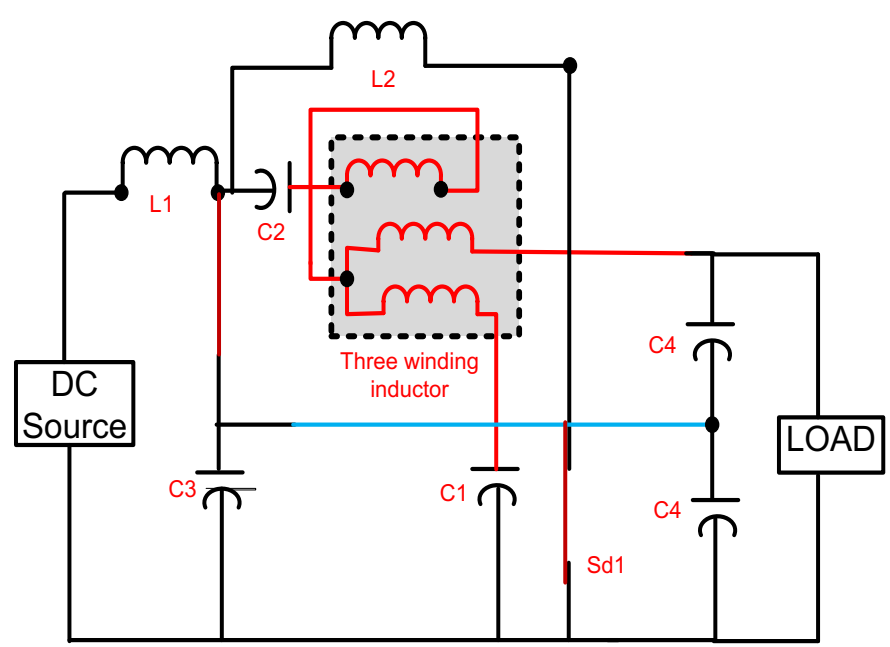

Figure 1b. Mode: 1 Switch ON and both diodes ON. 


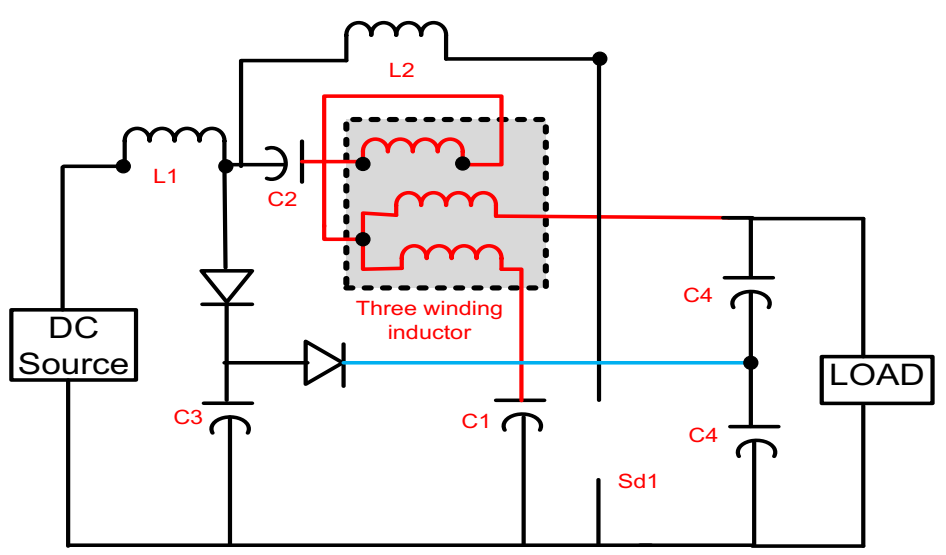

Figure 1c. Mode:2 Switch OFF and both diodes ON.

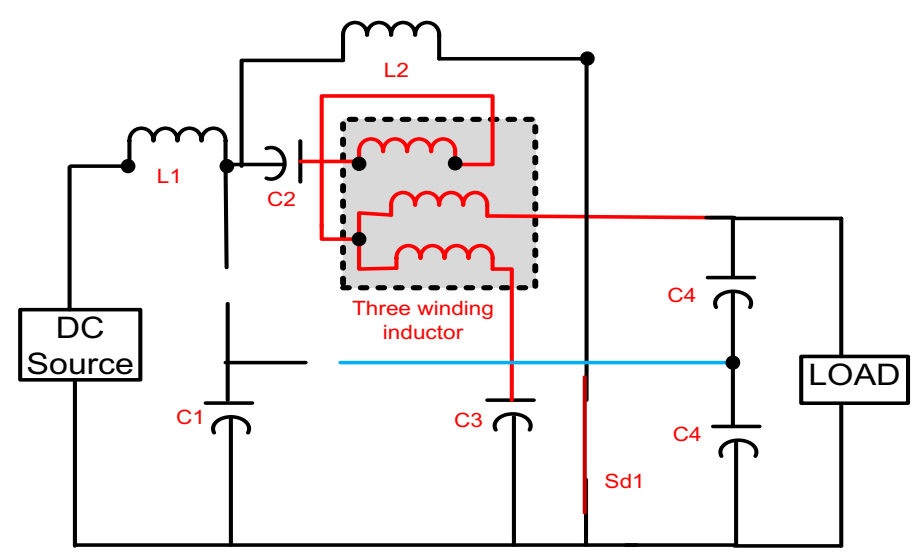

Figure 1d. Mode: 1 Switch ON and both diodes OFF.

With the switching operating under shoot-through (switch On and diodes off) and non-shoot-through (switch off and diodes On), the voltage equations can be written. Kirchhoff's voltage law is used for developing these equations. The shoot-through voltage equations are shown from equations (6a) to (6d).

$$
\begin{aligned}
& V_{L 1}-V_{c 2}+V_{N 1}+V_{N 2}+V_{c 1}-V_{d c}=0 \\
& V_{L 2}-V_{N 3}-V_{N 1}+V_{C 2}=0 \\
& -V_{C 1}-V_{N 2}+V_{N 3}=0 \\
& V_{L 1}+V_{L 2}-V_{d c}=0
\end{aligned}
$$

The non-shoot-through voltage equations are shown from equations (7a) to (7e): 
$V_{L 1}^{1}+V_{C 3}-V_{d c}=0$

$-V_{C 2}-V_{N 1}^{1}+V_{N 2}^{1}=0$

$-V_{C 3}+V_{C 1}=0$

$-V_{C 1}-V_{N 2}^{1}+V_{N 3}^{1}-V_{0}^{1}=0$

$V_{L 2}^{1}-V_{N 3}^{1}-V_{N 1}^{1}+V_{C 2}=0$

The three-winding transformer-based voltage step-up operation with turns ratio is shown in equation (7f).

$N_{1}: N_{2}: N_{3}=V_{N 1}: V_{N 2}: V_{N 3}=0$ and $V_{N 1}=V_{L W 1}$

The voltage balance equation can be written in terms of duty cycle $\mathrm{D}$ as

$V_{L 1} D+V_{L 1}^{1}(1-D)=0$

$V_{L 2} D+V_{L 2}^{1}(1-D)=0$

$V_{0} D+V_{0}^{1}(1-D)=0 \quad$ and

$V_{N 2} D+V_{N 2}^{1}(1-D)=0$

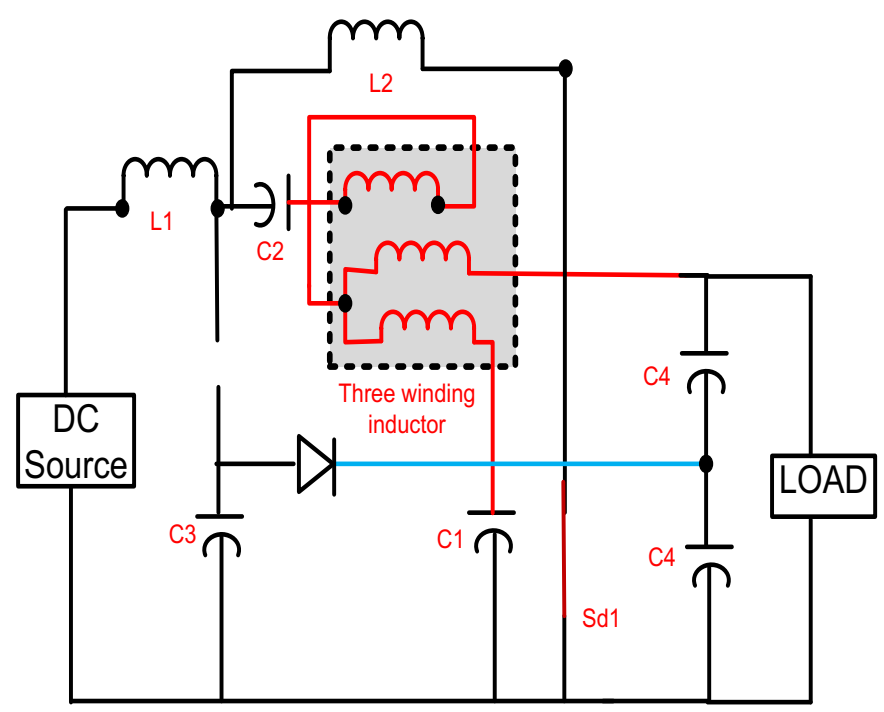

Figure 1e. Mode: 1 Switch ON and only one diodes ON. 


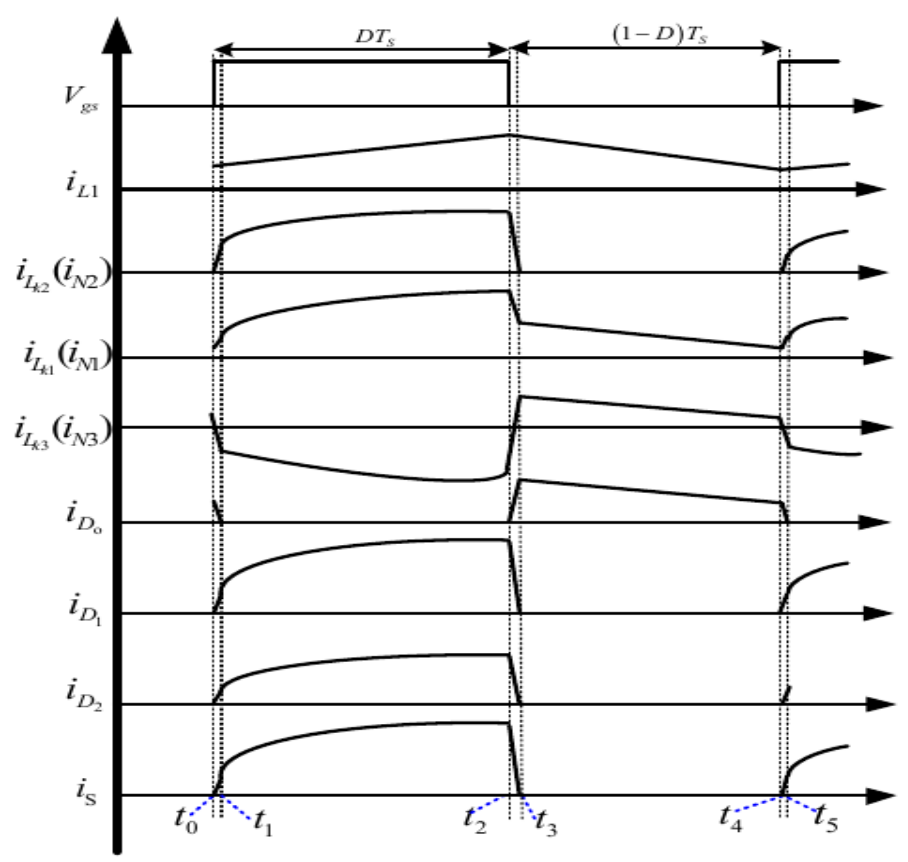

Figure 1f. Theoretical voltage and current waveforms.

Figure 1. Complete block diagram and modes of operation for the proposed YSC and the output waveforms with constant resistive load.

Using equations (7f) and (6c), and also using equation (8a), the $\mathrm{C} 1$ and $\mathrm{C} 2$ capacitor ypltages and $\mathrm{N} 2$ voltage equation are written in terms of turns rations and output voltage under non-shoot-through $\left(V_{0}\right)$ as shown in equation (9a).

$V_{C 1}=\frac{N_{2}}{N_{3}-N_{2}} V_{N 2}, V_{C 2}=\frac{N 1+N_{2}}{N_{2}} V_{N 2}$ and $V_{N 2}^{1}=\left(V_{0}^{1}+V_{C 1}\right) \frac{N_{2}}{N_{3}-N_{2}}$

Using equations (7c), (9a), and (8b), the capacitor $\mathrm{C}_{1}$ voltage can be written as in equation (9b) in terms of output voltage and duty cycle (D). Based on this equation, we can extract $\mathrm{N}_{2}$ turns voltage under shoot-through and nonshoot- through.

$V_{C 1}=-V_{0}^{1}(1-D)$

From (8d) and (9a), the ratio of $\mathrm{C} 1$ and $\mathrm{C} 2$ capacitor voltages can be written as in equation (9c).

$\frac{V_{C 1}}{V_{C 2}}=\left(\frac{N_{3}-N_{2}}{N_{1}+N_{2}}\right)\left(\frac{1-D}{-D}\right)$ or $\frac{V_{C 2}}{V_{C 1}}=\left(\frac{N_{1}+N_{2}}{N_{3}-N_{2}}\right)\left(\frac{1-D}{D}\right)$

Therefore, the winding factor can be stated as $K=\left(\frac{N_{1}+N_{2}}{N_{3}-N_{2}}\right)$ 
Using equations (9a) and (9b), the N2 turns voltage under non-shoot-through $\left(V_{N 2}^{1}\right)$

$V_{N 2}^{1}=\left(V_{0}^{1} D\right) \frac{N_{2}}{N_{3}-N_{2}}$

Using (8a), (8b), (7a), (7d), (9b), and (9e), the ratio of non-shoot-through inductor voltages can be written as in equation (9f).

$\frac{V_{L 1}^{1}}{V_{L 2}^{1}}=\frac{V_{0}^{1}(1-D)+V_{d c}}{V_{0}^{1} d}$

Now, the loop containing three-winding inductor, capacitor, is shown in equation (10) as

$$
V_{c 1}+\frac{N_{2}}{N_{1}} V_{L w 1}-\frac{N_{3}}{N_{1}} V_{L w 1}=0 \text { and therefore } V_{L w 1}=\frac{N_{1}}{N_{3}-N_{2}} V_{c 2}
$$

Now, KVL is applied for the loop with current flow though source DC voltage, inductor, capacitor C2, threewinding inductor, and capacitor $\mathrm{C} 1$ as in equation (11):

$V_{d c}-V_{L 1}+V_{c 2}-V_{L w 1}-\frac{N_{2}}{N_{1}} V_{L w 1}-V_{c 1}=0$ and so, $V_{L 1}=V_{d c}+V_{c 2}-\left(\frac{N_{1}+N_{2}}{N_{1}}\right) V_{L w 1}-V_{c 1}$

Now, considering the loop through the capacitor, the three-winding inductor and the load at overshoot (shortcircuited load) are given in equation (12):

$V_{c 2}-\frac{N_{3}}{N_{1}} V_{L w 1}-V_{L w 1}=0$ and from this $V_{L w 1}=\frac{N_{1}}{N_{3}+N_{1}} V_{c 2}$

Now, considering the load without overshoot and having output voltage Vo, the equation will be as in equation (13):

$V_{d c}-V_{L 1}-V o=0$

So, using equations (12) and (11), we get $V_{o}=V_{C 1}-V_{C 2}+\left(\frac{N_{1}+N_{2}}{N_{1}}\right) V_{L w 1}$

Substituting equations (10), (12) in equation (13) and writing it in terms of duty cycle (D) as in equation (15),

$\left(\frac{N_{1}}{N_{3}-N_{2}} V_{c 1}\right) D+\left(\frac{N_{1}}{N_{3}+N_{1}} V_{c 2}\right)(1-D)=0$ and hence $\frac{V_{c 2}}{V_{c 1}}=\left(\frac{N 1+N 3}{N 2-N 3}\right)\left(\frac{D}{1-D}\right)$

Further, considering the final mode as in Figure 1e, we will get equation (16):

$\left(V_{d c}+V_{C 2}-V_{c 1}-\left(\frac{N 1+N 2}{N 1}\right) V_{L w 1}\right) D+\left(V_{d c}+V_{C 2}-V_{c 1}-\left(\frac{N 1+N 2}{N 1}\right) V_{L 1}\right)(1-D)=0$ 
From all these equations $V_{C 1}=\frac{(1-D) V_{d c}}{\left(1-\left(\frac{N 1+N 2}{N 2-N 3}\right) D\right)}$ and $V_{C 2}=\frac{\left(\frac{N 1+N 2}{N 2-N 3}\right) D V_{d c}}{\left(1-\left(\frac{N 1+N 2}{N 2-N 3}\right) D\right)}$

Hence, the DC link voltages across the capacitors $\mathrm{C} 1$ and $\mathrm{C} 2$ are represented using equation (13), which is a function of duty cycle, three-winding turns (N1, N2, and N3), and input voltage Vdc. The theoretical waveforms for the proposed system under chopper operation with constant resistive load are shown in Figure 1f. Using (6b), (6d), (7d), (7f), and (9a), (9d), and (17), the shoot-through inductor voltage will be in terms of output voltage, duty cycle, and turns ratios as shown in equations $(18 \mathrm{a})$ to $(18 \mathrm{c})$ :

$$
\begin{aligned}
& V_{L 2}=\frac{N_{3} D-N_{1}-N_{3}-N_{2} D}{N_{2}(1-D)} V_{N 2} \text { or } V_{L 2}=\left(\frac{N_{3} D-N_{1}-N_{3}-N_{2} D}{N_{2}(1-D)}\right)\left(\frac{N_{2}-N_{3}}{N_{2}}\right) V_{0}^{1}(1-D) \\
& V_{L 1}=V_{d c}-\left(\frac{N_{3} D-N_{1}-N_{3}-N_{2} D}{N_{2}(1-D)}\right)\left(\frac{N_{2}-N_{3}}{N_{2}}\right) V_{0}^{1}(1-D) \\
& V_{N 2}^{1}=V_{0}^{1} D \frac{N_{2}}{N_{3}-N_{2}}
\end{aligned}
$$

From these equations, the duty cycle maximum allowable value is defined using equation (18d):

$$
D=1-\frac{N_{2}}{N_{3}}
$$

The relationship between output voltage and input voltage ratio, which is also known as voltage gain, can be written as

$$
\frac{V_{0}}{V_{d c}}=\frac{1}{1-K D}
$$

\section{Robustness of Y-Source Converter Three-Winding İnductor Analysis Using Dynamic Equations in State-Space Form}

The Y-source converter (YSC) main topology has three windings and a capacitor connected to the second winding. When observing the state space analysis, one winding current is enough to analyze the three windings as all the three windings will follow Faraday's law-based voltage and current division. Hence, for simplicity, the 1st winding inductor current is taken. So, the dynamic equation will have 1st winding inductor current and DC link voltage across the same arm capacitor $\mathrm{C} 1$ as shown in equation (19a) under shoot-through and (19b) for non-shoot-through: 
$\left[\begin{array}{c}0 \\ i_{N 1} \\ 0 \\ V_{c a p}\end{array}\right]=\left[\begin{array}{cc}0 & \frac{-N_{1}}{V_{L W}\left(N_{3}-N_{2}\right)} \\ \frac{-N_{1}}{\left(N_{3}-N_{2}\right)} & \frac{-N_{1}^{2}}{R_{m}\left(N_{3}-N_{2}\right)^{2}}\end{array}\right]\left[\begin{array}{c}i_{N 1} \\ V_{c a p}\end{array}\right]$ and

$\left[\begin{array}{c}0 \\ i_{N 1}^{1} \\ 0 \\ V_{c a p}^{1}\end{array}\right]=\left[\begin{array}{cc}0 & \frac{-N_{1}}{V_{L W}\left(N_{1}+N_{2}\right)} \\ \frac{-N_{1}}{C_{1}\left(N_{1}+N_{2}\right)} & \frac{-N_{1}^{2}}{R_{m} C_{1}\left(N_{1}+N_{2}\right)^{2}}\end{array}\right]\left[\begin{array}{c}i_{N 1}^{1} \\ V_{c a p}^{1}\end{array}\right]+\left[\begin{array}{cc}\frac{N_{1}}{V_{L W}\left(N_{1}+N_{2}\right)} & 0 \\ \frac{N_{1}^{2}}{R_{m} C_{1}\left(N_{1}+N_{2}\right)^{2}} & \frac{-\left(N_{1}+N_{3}\right)}{C_{1}\left(N_{1}+N_{2}\right)}\end{array}\right]\left[\begin{array}{c}V_{d c} \\ I_{0}^{1}\end{array}\right]$

The state equation input passive $(\mathrm{x})$ and active $(\mathrm{u})$ under steady-state $(\mathrm{X}$ or $\mathrm{U})$ and disturbance $\left({ }^{\wedge}\right)$ based state space representation:

$x=X+\hat{x}$ and $u=U+\hat{u}$, where steady-state passive and active component state vectors can be written as

$X=\left[\begin{array}{c}i_{N 1} \\ V_{c a p}\end{array}\right]$ and $U=\left[\begin{array}{c}V_{d c} \\ I_{0}\end{array}\right]$

$x$ and $u$ are disturbance parameters of the state variables. The dynamic disturbance expression can be written as

$\hat{x}=A \hat{x}+B \hat{u}$, initially assuming $\hat{x}(0) \cong 0$

Hence, the state variable disturbance vectors can be written as in equation (20c):

$\frac{x(s)}{\wedge}=(s I-A)^{-1} B$ and $\hat{V_{c a p}}(s)=\hat{V_{c a p 1}}(s)+\hat{V_{c a p}(s)}(s)=G_{1}(s) \hat{V_{d c}}(s)+G_{2}(s) \hat{i_{0}}(s)$

$u(s)$

where $a_{1}=0, a_{2}=\frac{D N_{1}\left(N_{1}+N_{2}\right)-(1-D) N_{1}\left(N_{3}-N_{2}\right)}{V_{L W}\left(N_{1}+N_{2}\right)\left(N_{3}-N_{2}\right)}, a_{3}=-a_{2} \frac{V_{L W}}{C_{1}}$ and

$a_{4}=\frac{-D N_{1}^{2}\left(N_{1}+N_{2}\right)^{2}-(1-D) N_{1}^{2}\left(N_{3}-N_{2}\right)^{2}}{R_{m} C_{1}\left(N_{1}+N_{2}\right)^{2}\left(N_{3}-N_{2}\right)^{2}}, b_{1}=\frac{(1-D) N_{1}}{V_{L W}\left(N_{1}+N_{2}\right)}, b_{2}=0$

$b_{3}=\frac{(1-D) N_{1}^{2}}{R_{m} C_{1}\left(N_{1}+N_{2}\right)^{2}}$ and $b_{4}=\frac{-(1-D)\left(N_{1}+N_{3}\right)}{C_{1}\left(N_{1}+N_{2}\right)}$ 


$$
\begin{aligned}
& G_{1}(s)=\left.\frac{\hat{V_{c a p}}(s)}{\hat{V_{d c}}(s)}\right|_{i_{0}(s)=0}=\frac{b_{3} s+\left(a_{3} b_{1}-a_{1} b_{3}\right)}{s^{2}-s\left(a_{1}+a_{4}\right)+\left(a_{1} a_{4}-a_{2} a_{3}\right)} \\
& G_{2}(s)=\left.\frac{\hat{V_{c a p}}(s)}{\hat{i_{0}}(s)}\right|_{V_{d c}(s)=0}=\frac{b_{4} s+\left(a_{3} b_{1}-a_{1} b_{2}\right)}{s^{2}-s\left(a_{1}+a_{4}\right)+\left(a_{1} a_{4}-a_{2} a_{3}\right)}
\end{aligned}
$$

The transfer function form of capacitor voltage is shown in equation (20c) under DC supply when the switch $\mathrm{Sd} 1$ is off when (Io) is absent, and the second expression when the switch is closed. The Bode plot based characteristic curve for the transfer functions G1 and G2 is shown in Figs. 2a at 0.2 duty cycle. There is a sudden change in the $\mathrm{G} 1(\mathrm{~s})$ and $\mathrm{G} 2(\mathrm{~s})$ at $60 \mathrm{~Hz}$, so disturbance variation across the capacitor will be easily understood based on this plot. With the increase in the capacitor value, the operating frequency decreases. Therefore, the system is robust for rapid switching operation under lower switching duty cycle. Under duty cycle beyond 0.5 as in Figure 2(b), there is a dangerous voltage across the three-arm inductor, large fluctuations in the capacitor voltage are observed, and the solid-state switches and diodes produce heat, and slowly the system becomes unstable. Hence, robustness of system is observed for different switching cycles and capacitor values.

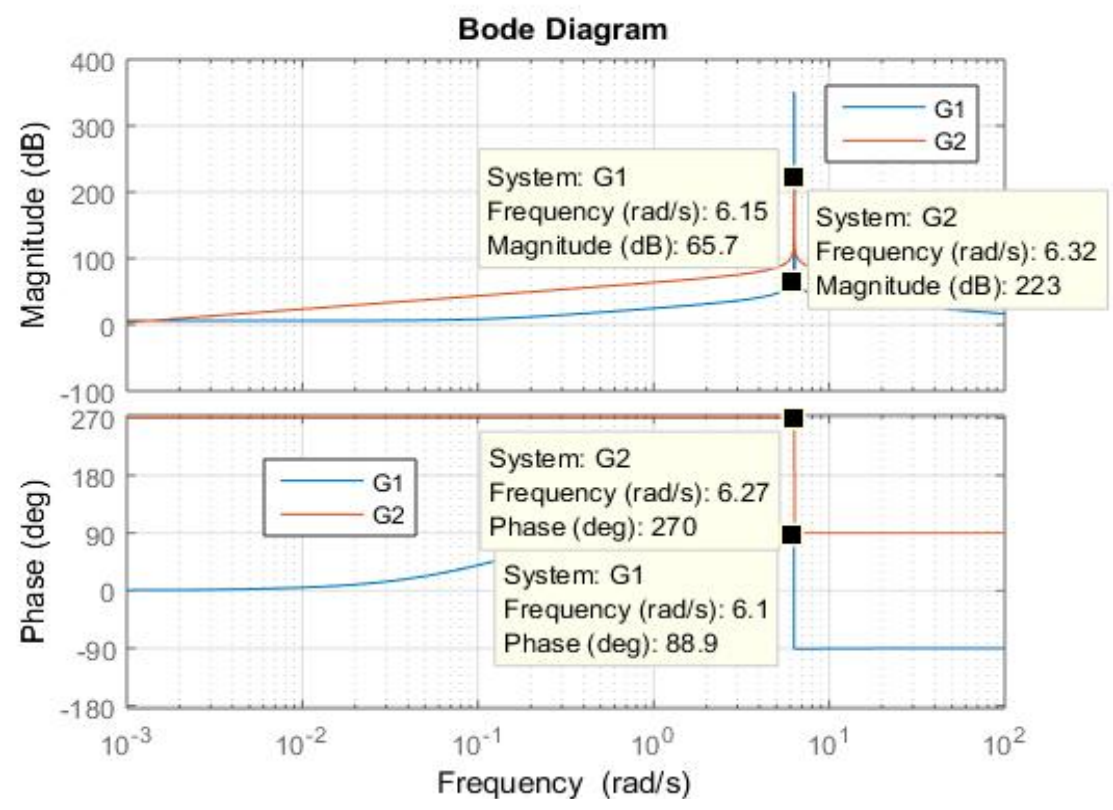

Figure 2(a). Low switching duty cycle $(\mathrm{D}=0.2)$. 


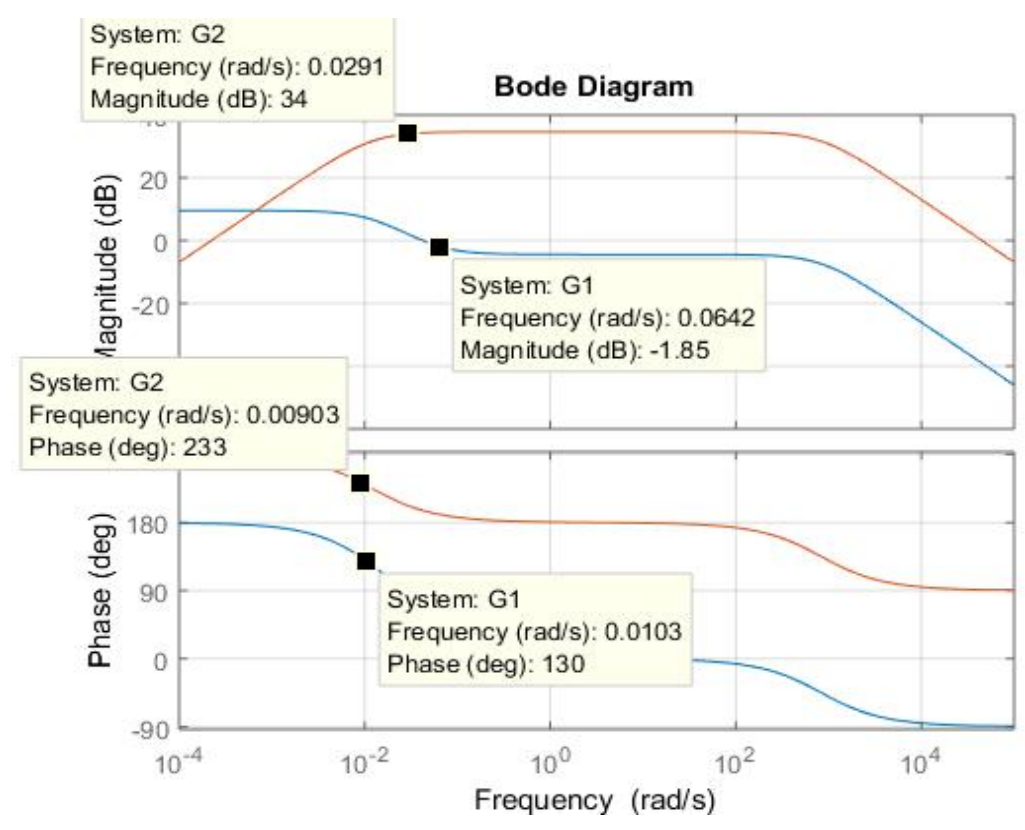

Figure 2(a). High switching duty cycle $(\mathrm{D}=0.5)$.

Figure 2. Open loop characteristics of the capacitor voltage based on (a) low switching operation and (b) high switching duty cycle for transfer functions G1(s) and G2(s).

\section{Y-source DC-DC converter control strategy for speed, torque control, and ripples reduction}

The complete bock diagram for the BLDC motor control scheme is shown in Figure 3. The control circuit is developed for effective speed and torque control with minimum torque ripples. To achieve this, $\mathrm{Y}$-source converter topology, which is an improved version of [36], is adopted with the operation as described in the section III. The inverter control scheme is designed to track the speed error input and to maintain it to the lowest value (zero), and the output current reference with an aptitude with least possible ripples. The inverter is a conventional six-pulse circuit that is developed to produce trapezoidal emf with speed and torque control. The block diagram of the BLDC control circuit is shown in Figure 3a.

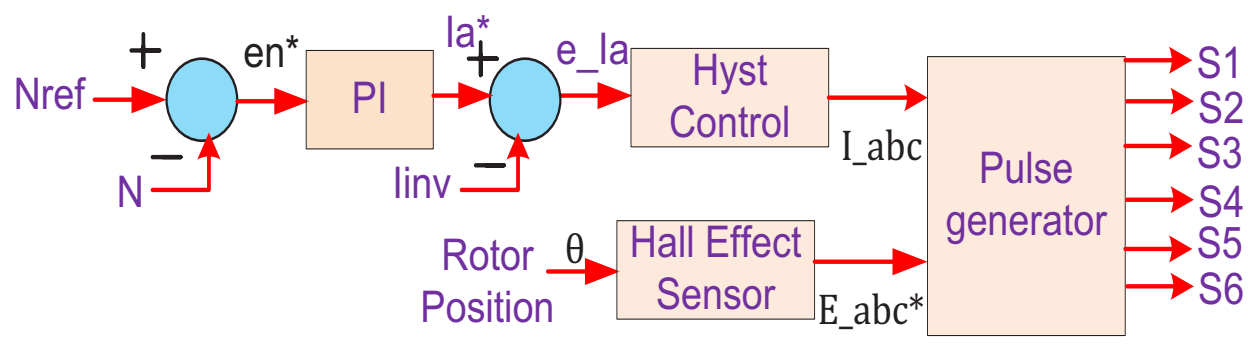

Figure 3a. Pulse generator internal circuit block diagram. 


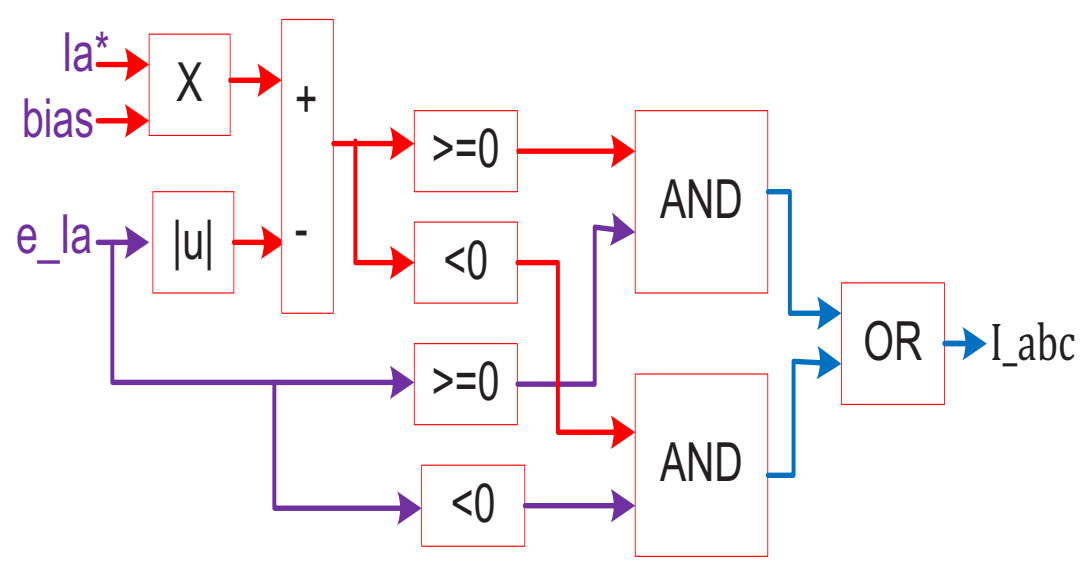

Figure 3b. Hysteresis current control scheme.

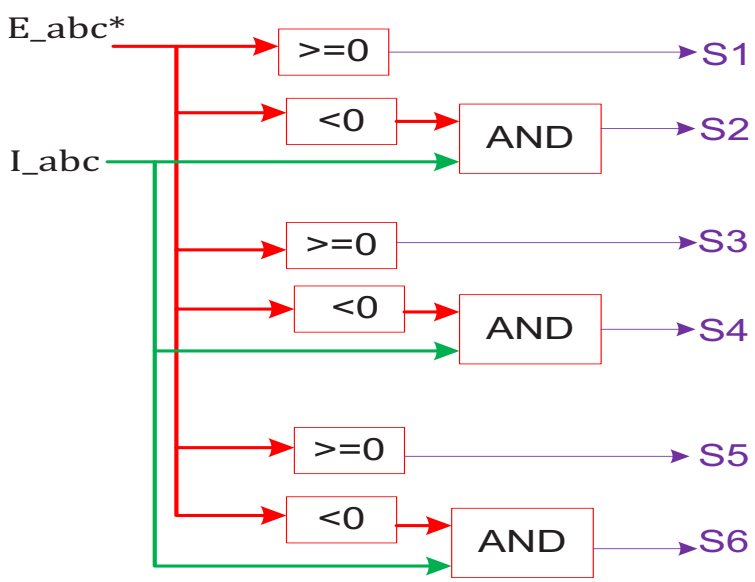

Figure 3c. Pulse generator internal circuit block diagram.

Figure 3. Control circuit of BLDC motor for torque ripple reduction.

The speed of the rotor is the input, and the seven switching pulses (S1 to S7) are output for this figure. Here, the reference speed (Nref) and actual speed (N) are compared, and the speed error signal (en*) is given to the PI controller to get reference DC current called (Ia*). The actual DC current is the current passing through the 6 switch pulses (Iinv), and this reference current $\mathrm{Ia}^{*}$ is compared, and the current error (e_Ia) is given to the hysteresis controller. The output of this hysteresis controller is three-phase reference currents (Iabc), and the block diagram is shown in Figure 3b. The rotor position is sensed by the Hall Effect sensor and will give reference back-emf (E_abc*). This is a conventional method to achieve the reference back-emf voltage. The Hall Effect sensor based switching working scheme is shown in Table 1. The reference three-phase currents and reference back-emf are given to the pulse generator to get the six pulses for the respective switches, and their internal block diagram is shown in Figure $3 \mathrm{c}$.

The hysteresis current control scheme internal block diagram is shown in Figure 3b. Here, Ia* is the reference current obtained from PI controller output, and bias is a constant value. The error current signal is e_Ia along with 
Ia* and bias compared with zero signal and logic technique to get the reference three phase current. The seven IGBT pulses will be getting pulses using the reference back emf voltage Eabc* and reference hysteresis controller current Iabc by comparing them as shown in Figure 3c. The internal block diagrams in Figure 3b and Figure $3 \mathrm{c}$ describe the hysteresis current control scheme and internal pulse generation circuit block diagram. The switching logic table for the pulse generation scheme for the seven switch inverter scheme is shown in Table 2. Based on the back-emf input value, the switching On and OFF are decided based on this mechanism. The en* is the speed error input value.

Table 1. Hysteresis block working table.

\begin{tabular}{|c|c|c|c|c|c|}
\hline Ha & Hb & Hc & EMF_a & EMF_b & EMF_c \\
\hline 0 & 0 & 0 & 0 & 0 & 0 \\
\hline 0 & 0 & 1 & 0 & -1 & +1 \\
\hline 0 & 1 & 0 & -1 & +1 & 0 \\
\hline 0 & 1 & 1 & -1 & 0 & +1 \\
\hline 1 & 0 & 0 & +1 & 0 & -1 \\
\hline 1 & 0 & 1 & +1 & -1 & 0 \\
\hline 1 & 1 & 0 & 0 & +1 & -1 \\
\hline 1 & 1 & 1 & 0 & 0 & 0 \\
\hline
\end{tabular}

Table 2. Pulse Generator switching table.

\begin{tabular}{|c|c|c|c|c|c|c|c|c|c|}
\hline EMF_a & EMF_b & EMF_c & S1 & S2 & S3 & S4 & S5 & S6 & S7 \\
\hline 0 & 0 & 0 & 0 & 0 & 0 & 0 & 0 & 0 & 0 \\
\hline 0 & -1 & 1 & 0 & 0 & 0 & 1 & 1 & 1 & 1 \\
\hline-1 & 1 & 0 & 0 & 1 & 1 & 0 & 0 & 0 & 1 \\
\hline-1 & 0 & 1 & 1 & 0 & 0 & 0 & 0 & 1 & 1 \\
\hline 1 & 0 & -1 & 0 & 1 & 0 & 0 & 1 & 0 & 1 \\
\hline 1 & -1 & 0 & 1 & 0 & 0 & 1 & 0 & 0 & 1 \\
\hline 0 & 1 & -1 & 0 & 0 & 1 & 0 & 0 & 1 & 1 \\
\hline
\end{tabular}

\section{RESULTS AND DİSCUSSION}

The performance of BLDC motor system with conventional sensor based BLDC system with field oriented control logic and PI based speed error controller is compared with the Z-Source converter (ZSC) Xia, Kun (2016) and with the proposed Y-source converter (YSC) for the control scheme described in earlier section with six switches being considered for the analysis. The speed and torque control along with speed and torque ripples are considered for the analysis. The BLDC parameters like armature one phase current, back-emf of the same phase, load torque and 
electromagnetic torque (EMT), reference and actual speed, and DC link capacitor voltage are compared for the analysis. Further, inverter three-phase voltage and current, ZSC, and YSC input and output waveforms are also considered to show the efficacy of the proposed work. They are observed under the following cases: the first case with constant speed and variable torque control, the second case with constant torque and variable speed control, and the final case with both speed and torque variation with respect to time.

\subsection{Case A: YSC Operation Under Different Voltage Reference Values}

The operation of the YSC DC-DC converter is discussed in this section with the circuit shown in Figure1(a) under closed loop operation with variable output reference voltage as shown in Figure 4. The reference output voltage across the load (black) and the actual DC voltage (red) is shown in Figure 4a. It can be observed that, with input voltage 6 of $40 \mathrm{~V}$, the output voltage reached is 200,250 , and $300 \mathrm{~V}$ set value. Under very high voltage reference value, the duty cycle is increasing beyond 0.5 value, and voltage oscillations can be observed, and beyond this, the stability will be lost, and voltage drops as per Figure 2 explanation about the circuit robustness. The PI controller also reaches zero value under different voltage values, and the system is stable and controllable. The efficiency shown in Figure $4 \mathrm{~b}$ with 200 and $250 \mathrm{~V}$ being about $95 \%$ and with $300 \mathrm{~V}$ being $90 \%$ on average. The 1st winding of the three-winding circle solenoid inductor voltage and current is shown in Figure 4c, where the voltage blocking is for more time than it is operating due to lower duty cycle. The second diode connecting both the capacitors voltage and current is shown in Figure 4d, where the current is negative in polarity compared to its voltage, which implies the bidirectional operation achievable with this diode operation under Figure 1e operation.
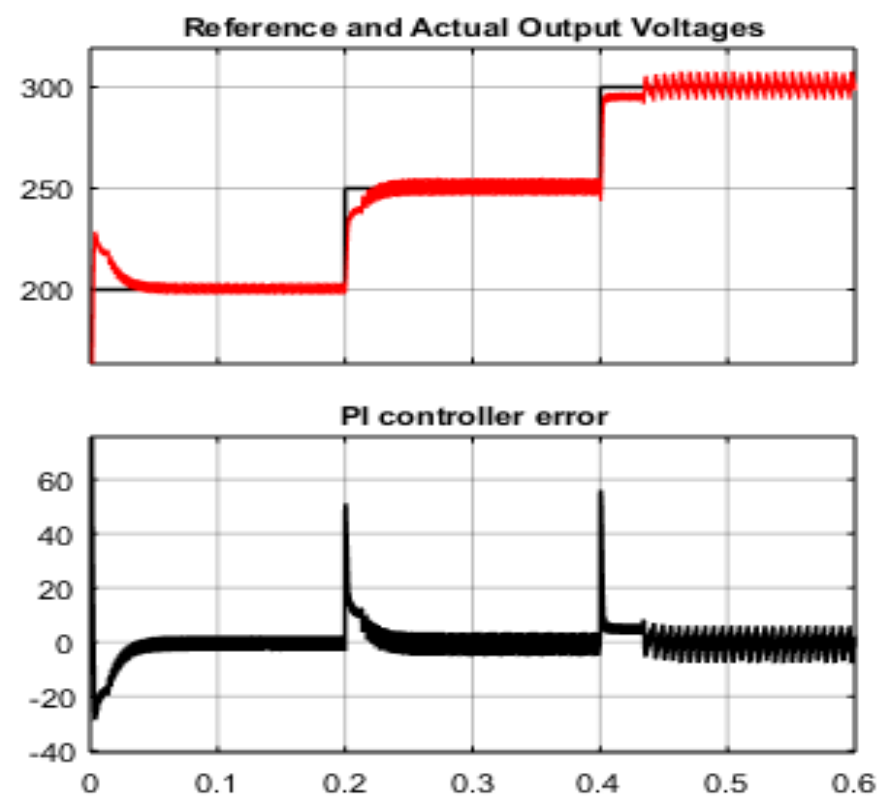

Figure 4a. YSC DC-DC operation with voltage step operation (top) and PI controller output (bottom). 


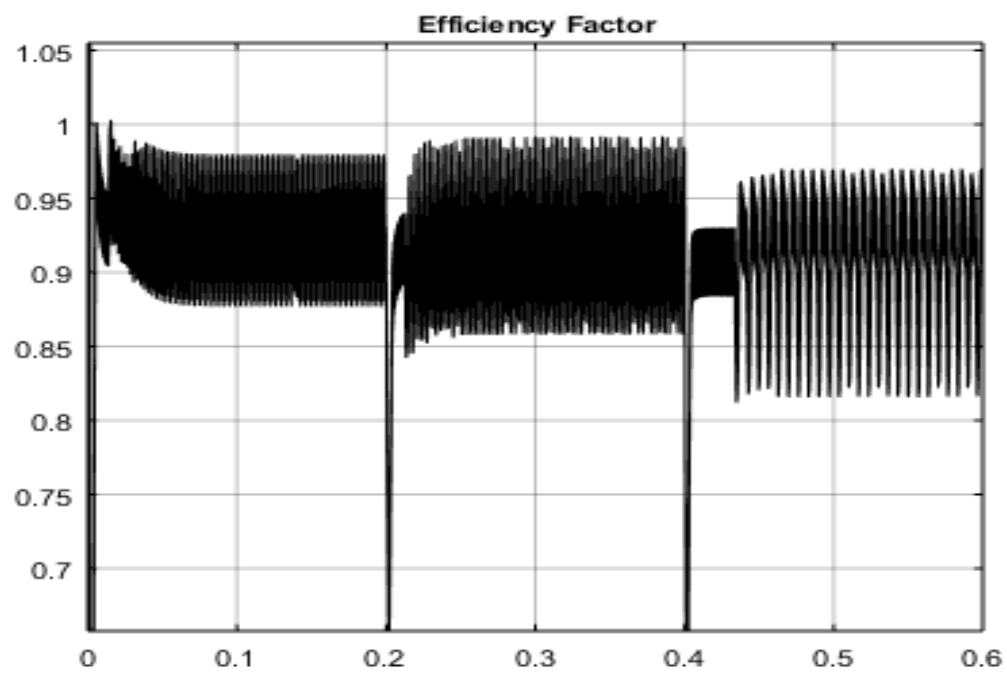

Figure 4b. Efficiency.

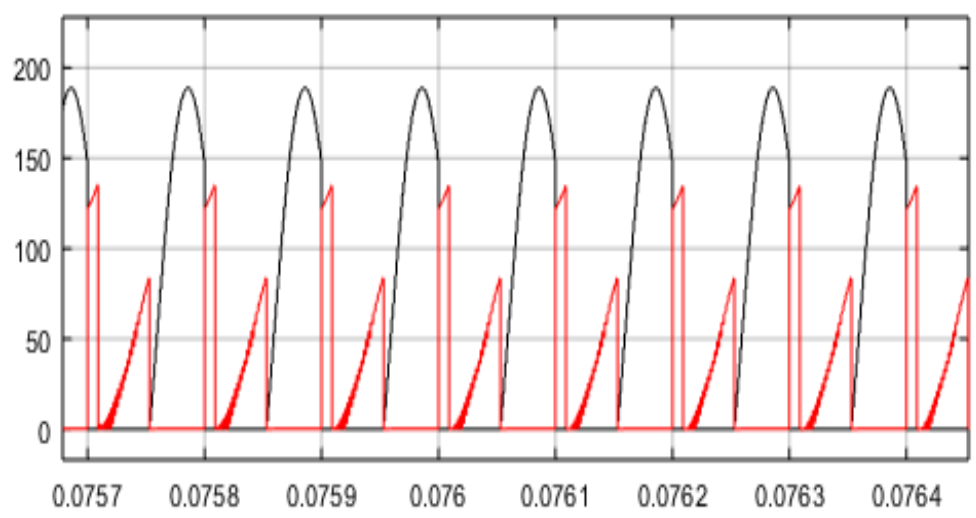

Figure 4c. Black is voltage, and red is current for the 1st winding.

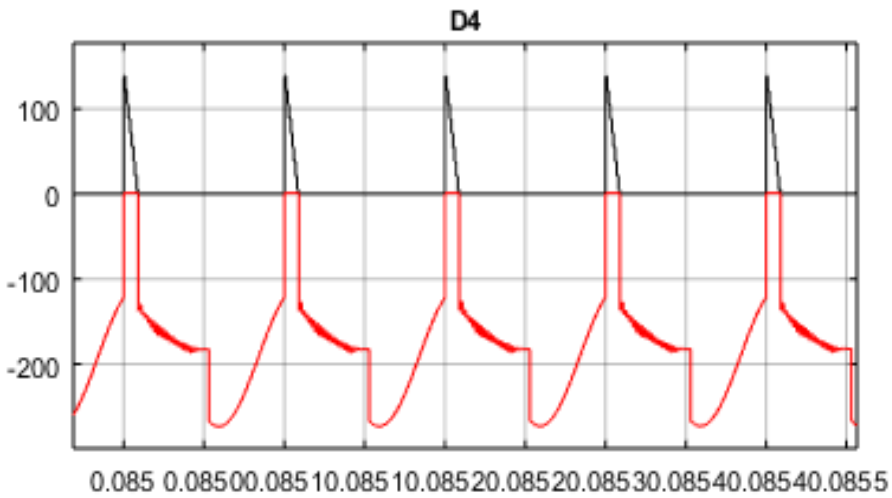

Figure 4c. Diode D2 voltage and current (red). 


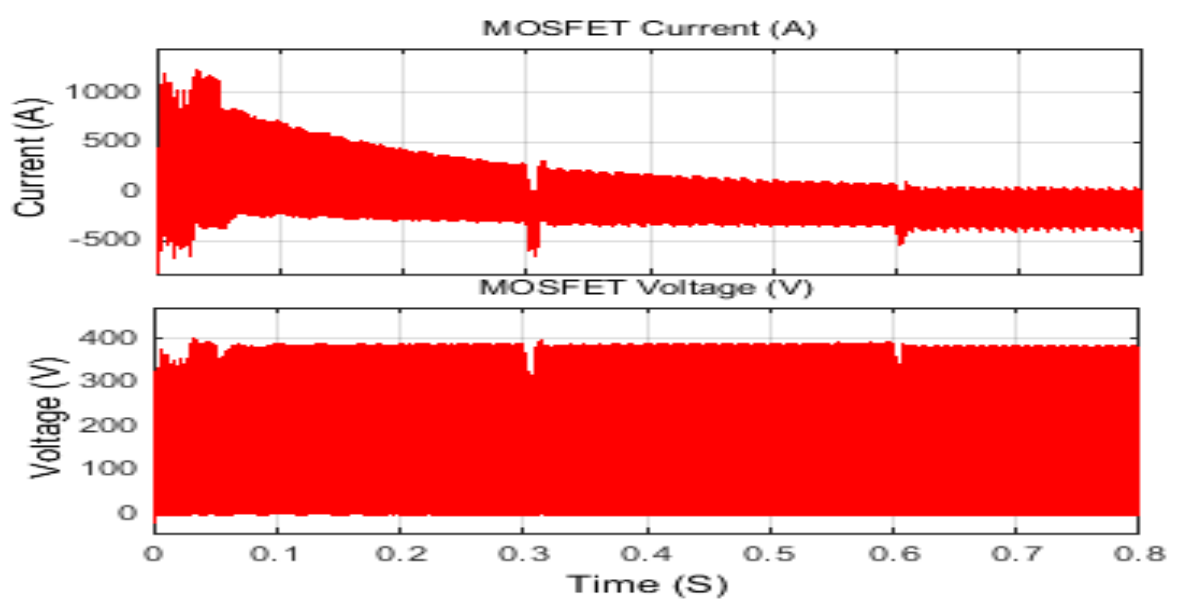

Figure 4d. MOSFET voltage and current for YSC.

Figure 4. Output waveforms for the YSC under variable output voltage reference.

The MOSFET voltage with YSC is $330 \mathrm{~V}$ maximum, and the current is 400A when motor is at start as shown in Figure 4d. Here, the current waveform is also DC and is increasing with increase in load. The stress current is maximum with 200A under heavy loaded condition and increasing for few milliseconds to $300 \mathrm{~A}$ to meet the load demand. Hence, the voltage and current stress under steady-state, transient, and at the starting are also less with the present method.

\subsection{Case A: Constant Speed and Variable Torque Control of BLDC Motor}

The test system with YSC for BLDC motor load is shown in Figure 5. In this, the BLDC motor is operated under constant speed at 1500rpm, and the load torque is varying from $15 \mathrm{Nm}$ to $30 \mathrm{Nm}$ at $0.05 \mathrm{~s}$, later to $40 \mathrm{Nm}$ at $0.1 \mathrm{~s}$ and finally to $60 \mathrm{Nm}$ at $0.15 \mathrm{~s}$. The waveforms for the conventional control scheme with ZSC and proposed YSC inverter configuration are shown from Figure 4 to Figure 6. In Figure $6 \mathrm{a}$ and $6 \mathrm{~b}$, the BLDC motor parameters and DC link capacitor voltage are shown with ZSC and YSC. The BLDC A-phase stator current using conventional technique having distorted trapezoidal waveform with notches is observed in Figure 6a (top), while with YSC, the current waveform is trapezoidal as in Figure $6 \mathrm{~b}$ (top). The stator current can be observed to be increasing with the increase in the load torque. When compared with the conventional and proposed topologies and control scheme, the back-emf decreased when the load is increased to $60 \mathrm{~N}$-m with conventional technique, whereas with the proposed technique, this voltage is constant in amplitude. Hence, the developed torque is sufficient to carry the increased load demand on the motor effectively with the proposed technique. 


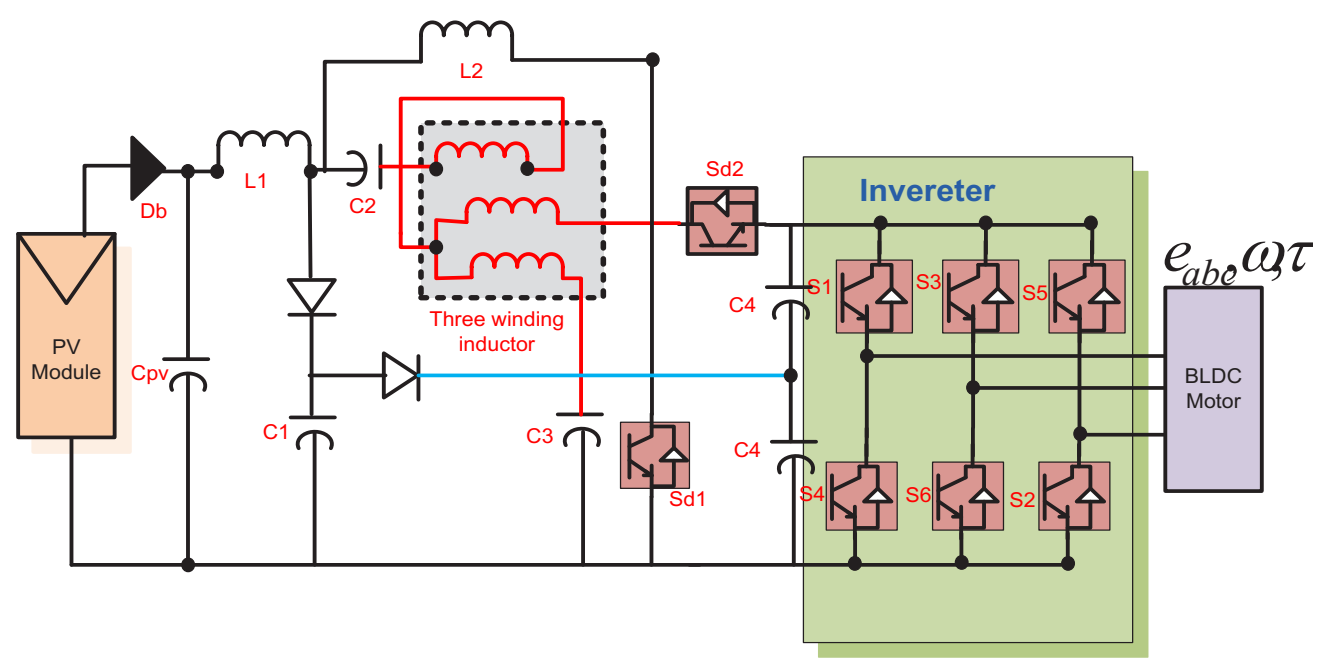

Figure 5. Test bed system with Y-source converter and six-switch inverter to drive a BLDC motor load.

The reference load torque is shown in black line, and the actual electromagnetic torque (EMT) is shown in red color waveform for both conventional and proposed strategies. It is observed that the starting EMT surges are almost the same for both techniques, and this subtransient surge is observed till the motor reaches its desired speed. It can be observed that there are more ripples in the torque waveform with conventional technique. With the conventional technique, when the reference torque is set at $15 \mathrm{~N}-\mathrm{m}$, the EMT is varying from 0 to $25 \mathrm{~N}-\mathrm{m}$ from the start till $0.05 \mathrm{~s}$. When the reference load torque changed to $30 \mathrm{~N}-\mathrm{m}$ at $0.1 \mathrm{~s}$, this EMT is fluctuating from 20 to $40 \mathrm{~N}-\mathrm{m}$. Similarly, the EMT is varying from 63 to $27 \mathrm{~N}$-m when load torque shifted to $40 \mathrm{Nm}$. The ripples slowly decreased with the range from 30 to $50 \mathrm{Nm}$.
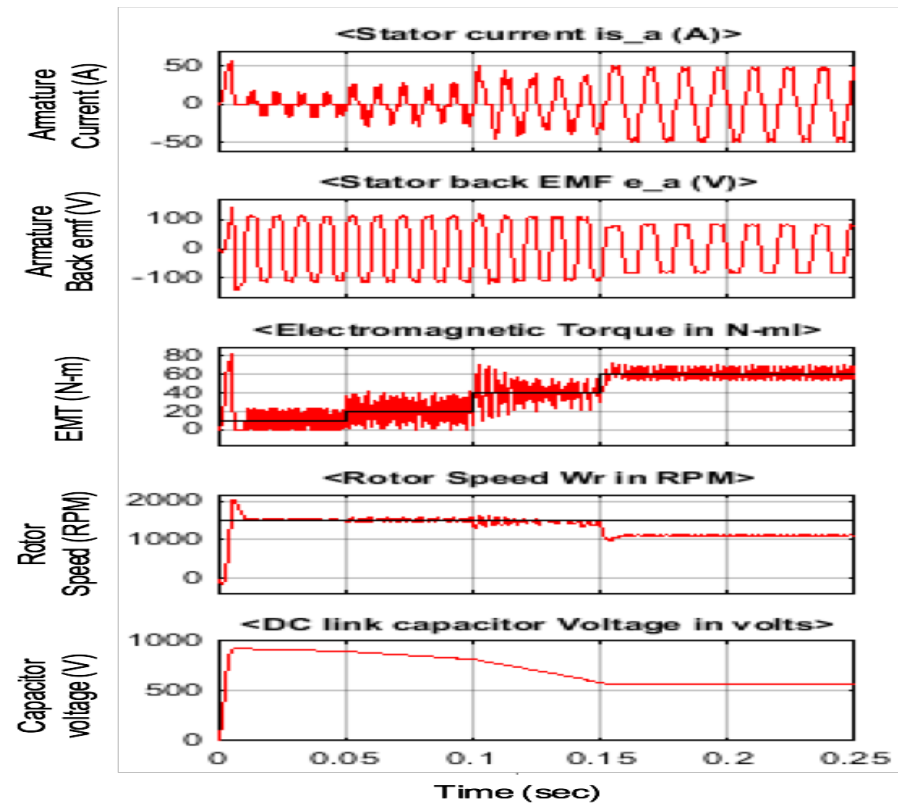

Figure 6a. BLDC motor parameters and DC link capacitor voltage with ZSC. 


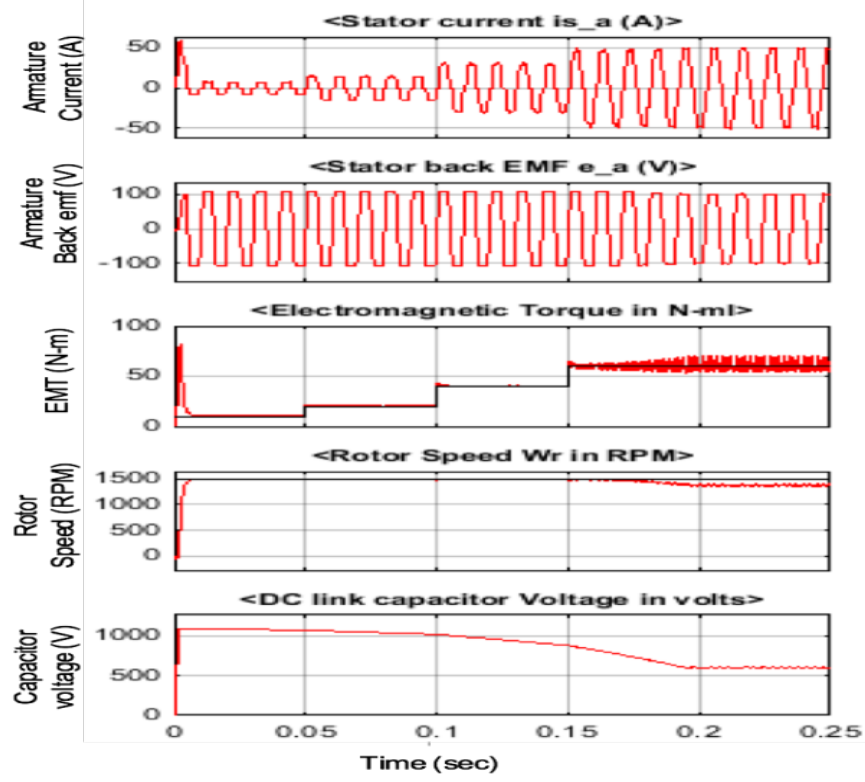

Figure 6b. YSC under constant speed and variable torque case study.

The rotor speed with both control schemes is shown here under variable load torque and constant speed case study. There is an overshoot in the rotor speed with conventional technique and also few sustained oscillations observed when the load torque is changing suddenly at $40 \mathrm{~N}-\mathrm{m}$. When the load suddenly increased to $60 \mathrm{~N}-\mathrm{m}$, the speed of the rotor is decreased from reference $1500 \mathrm{rpm}$ to $1100 \mathrm{rpm}$ due to decrease in the back-emf developed. So, with increase in the load above $45 \mathrm{~N}$-m, which is $75 \%$ rated value, there is a drop in the speed curve due to the permanent magnet behavior of the rotor and control circuit unable to supply desired back-emf. With the YSC design proposed, the rotor speed is almost constant at desired $1500 \mathrm{rpm}$, and all load reaches $40 \mathrm{~N}-\mathrm{m}$ value. When suddenly load torque increased to $60 \mathrm{~N}-\mathrm{m}$, this rotor speed dropped, but the slip in the speed value changed from desired $1500 \mathrm{rpm}$ to 1400 $\mathrm{rpm}$. Hence, in terms of speed control and torque control, the proposed method is advantageous with better performance in all aspects. The performance of the proposed technique is comparatively improved when compared with the latest work in Xia, Kun, (2016).

When the DC link voltage across the capacitor is observed for both ZSC and YSC topologies, with increase in the load torque, the DC link voltage is decreasing for both cases, but this drop is considerably high with conventional ZSC than with YSC. Initially, at $15 \mathrm{~N}-\mathrm{m}$ load torque, the DC link voltage is $900 \mathrm{~V}$ for conventional and $1100 \mathrm{~V}$ for proposed. This voltage is decreased slowly to $800 \mathrm{~V}$ when torque increased o $30 \mathrm{~N}-\mathrm{m}$ for conventional and $1000 \mathrm{~V}$ for proposed. When load further increased to $40 \mathrm{~N}-\mathrm{m}$, the voltage decreased further slowly to $550 \mathrm{~N}-\mathrm{m}$ with conventional and $900 \mathrm{~V}$ for proposed. When load finally reached $60 \mathrm{~N}-\mathrm{m}$, the DC link voltage is constant at 550V with being conventional from 0.15 seconds, but with the proposed one, this capacitor voltage decreased slowly to $550 \mathrm{~N}-\mathrm{m}$ for few seconds and later remained constant at 550V.

The inverter voltage and current waveforms for this case with conventional ZSC and proposed YSC based inverter control scheme are shown in Figs. $7 \mathrm{a}$ and $7 \mathrm{~b}$. The voltage waveform is distorted and not trapezoidal of constant amplitude with conventional scheme. Here, the voltage is fluctuating and decreasing with the increase in the load value due to the change in the capacitor voltage value. At light load, the inverter voltage is $800 \mathrm{~V}$, and it is decreased to $600 \mathrm{~V}$ phase to phase. But when the torque increased to $60 \mathrm{~N}-\mathrm{m}$, the DC link voltage remained constant at $600 \mathrm{~V}$, and the waveform got better. This is due to the change in the capacitor voltage value and also because of the PI output 
current ripple value. The current waveform is also having similar distortions with conventional technique. When the same voltage and currents are observed with the proposed YSC topology, the voltage waveform is having the same amplitude under the same load torque as capacitor voltage is almost constant as shown in Figure $7 \mathrm{~b}$ bottom right. But when the load torque is increased to rated value of $60 \mathrm{~N}-\mathrm{m}$ as shown in Figure $7 \mathrm{~b}$, which is often the case, there is a decrease in the inverter voltage due to decrease in the capacitor link voltage. But the current three-phase waveform is constant when the load is constant, but it is increased and maintained constant in aptitude as the load torque is increased. When the load is at $15 \mathrm{~N}-\mathrm{m}$, the current is $8 \mathrm{~A}$, and it increased to $17 \mathrm{~A}$ when the load increased to $30 \mathrm{~N}-\mathrm{m}$. This current further increased to 30A when the load reached $40 \mathrm{~N}-\mathrm{m}$, and finally, when the load became $60 \mathrm{~N}-\mathrm{m}$, the inverter current is 51A. The distortions in current and voltage waveforms are lesser with the proposed control scheme.

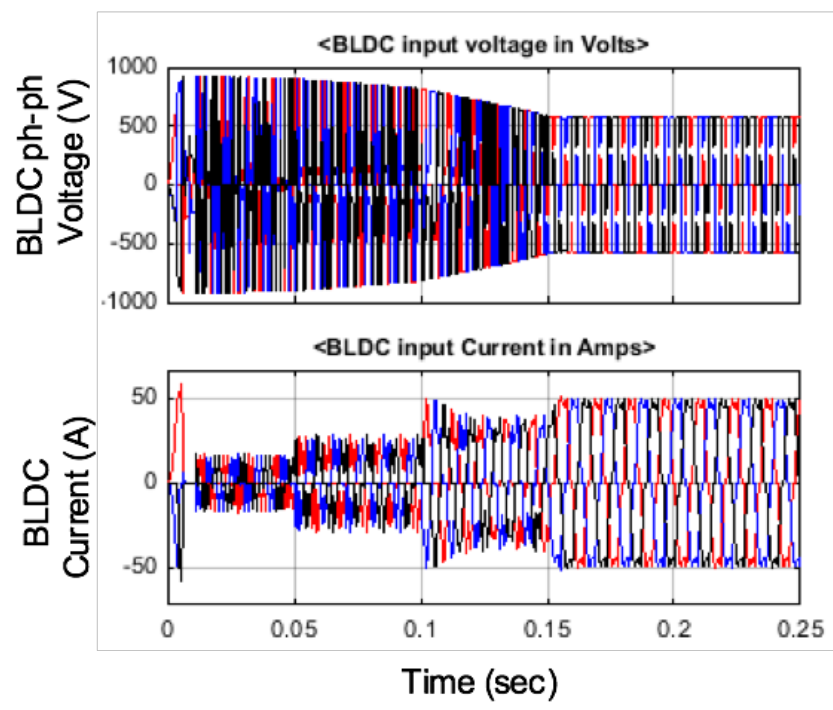

Figure 7a. BLDC motor inverter voltage and current with ZSC.

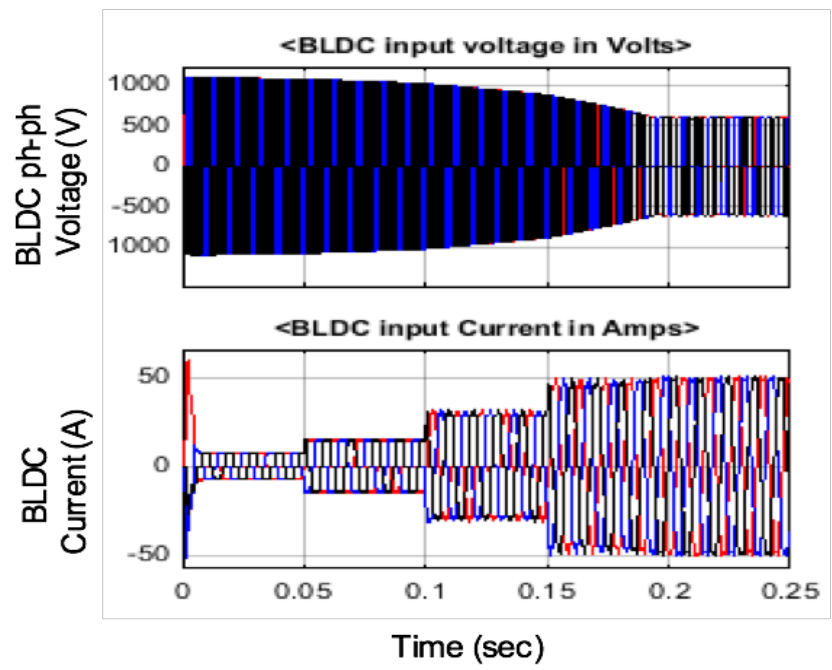

Figure 7b. YSC. 
Now, at $0.15 \mathrm{~s}$, this load torque increased suddenly to $60 \mathrm{~N}-\mathrm{m}$; during this period, the surges are lesser at this load with variation from 50-70 Nm. Hence, there are more surges with this control scheme. The reason for large ripples is due to the fact that the output of ZSC is having large ripples as shown in Figure 7a. The current ripples are very high till $0.15 \mathrm{~s}$, so torque ripples are also high. The same dynamic analysis for the EMT is analyzed when YSC and inverter are used. The starting surge is almost the same for both techniques, but the ripples are very less when the load torque is up to $40 \mathrm{~N}-\mathrm{m}$. But when this load torque increased to $60 \mathrm{~N}-\mathrm{m}$, there are few ripples observed in this from $0.15 \mathrm{~s}$. This is because the motor is extracting more current from the stator to drive this heavy load. But due to permanent magnet behavior of rotor, more decomposition of flux is difficult to obtain. However, with the proposed technique, the ripples are comparatively less. The YSC output is having lesser ripple when the load torque is low, but this rippled got increased considerably when the load torque is increased to $60 \mathrm{~N}-\mathrm{m}$.

When considering the ZSC case, initially, rotor speed is increasing from zero to $1500 \mathrm{rpm}$. So, rotor rotated in opposite direction at the beginning for little time started to rotate in forward direction. Hence, the PI error input value started from 1550 value and is decreasing. With ZSC, the rotor speed increased beyond 1500rpm for few seconds, so the PI error input extended to -400 value and settled at near zero value later at the load of $15 \mathrm{~N}-\mathrm{m}$. The reason for the overshoot or undershoot is because of the integral parameter constant value. If this value is decreased, the settling time will be increased, which is not desired in general for a BLDC motor for general applications. The speed error or input to the PI controller is controlled effectively with well-tuned PI controller. But, when the load increased to higher values, the PI controller behavior got disturbed, and hence, there is a diversion in error value. The PI controller output is current reference. If it is observed that PI input is well controlled, the output is having large fluctuations. The PI saturation block limits helped control the current to $50 \mathrm{~A}$ peak to peak. It can be observed that the error value is maintained almost to zero value till the load is $40 \mathrm{~N}-\mathrm{m}$ and a small deviation of 100. The YSC topology based output is maintained at small value, but some surges are observed when load changes take place. However, when the load change is very high, that is, at $60 \mathrm{~N}-\mathrm{m}$, the YSC and control scheme proposed based output are also having ripples but are smaller compared to ZSC.

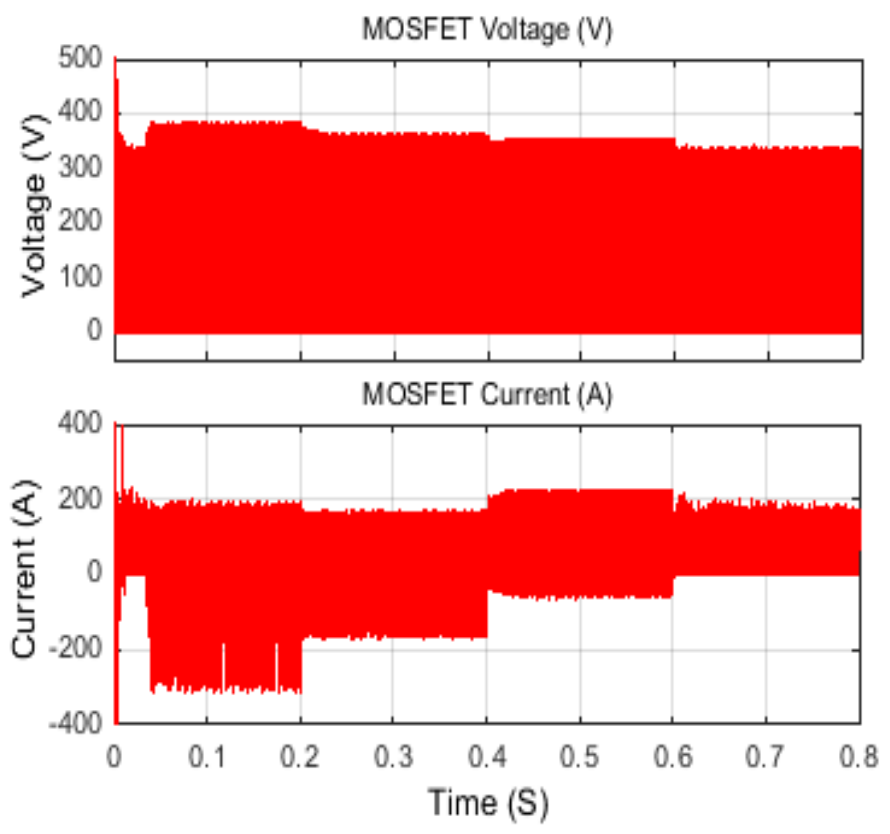

Figure 7c(i). MOSFET voltage and current with buck-boost chopper for [31] method. 

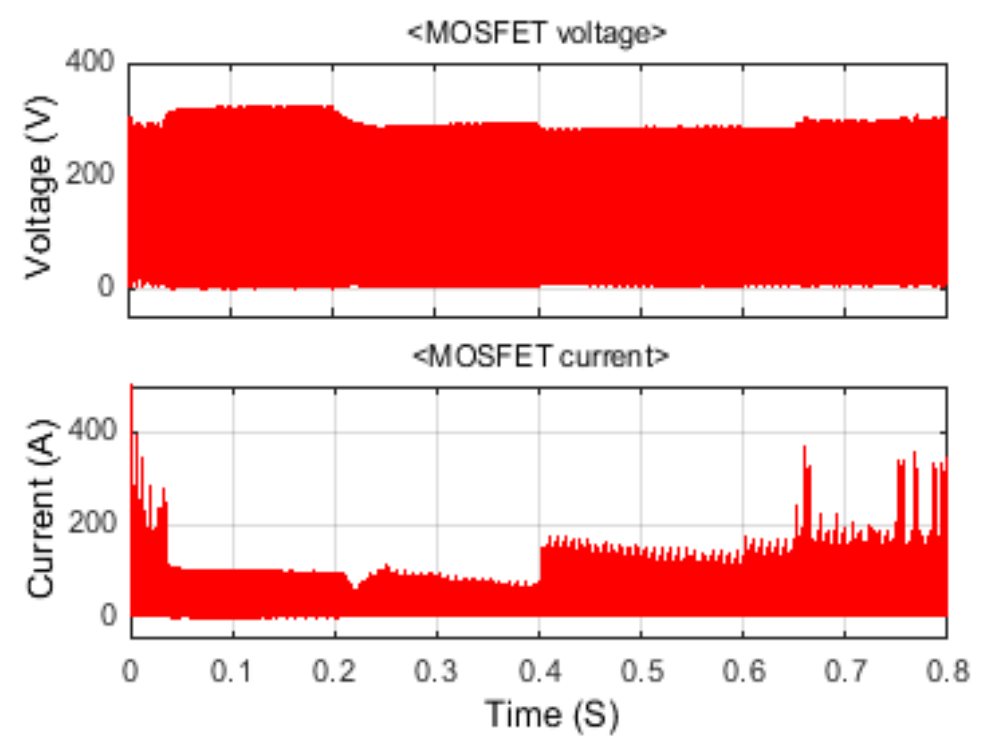

Figure 7c(ii). MOSFET voltage and current for YSC.

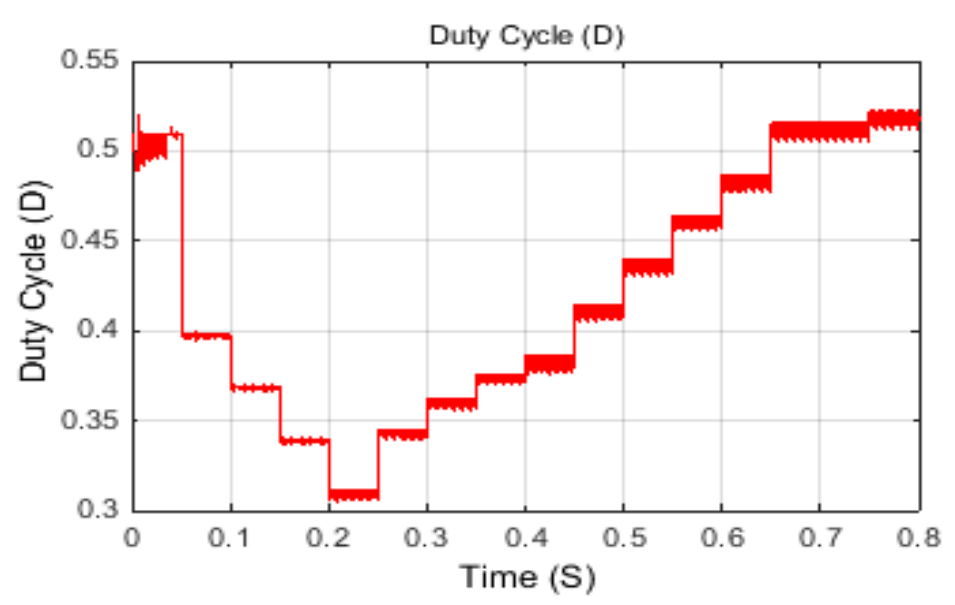

Figure 7d. Duty cycle with the YSC.

Figure 7. Output waveforms for the two methods under constant rotor speed and variable load torque.

Hence, from this case study, it can be understood that the YSC performance is superior to ZSC controller in maintaining the speed and controlling the torque. The torque ripples are minimized, torque and speed surges are curtailed, and overall performance is improved. With the proposed technique, heavy load can operate effectively on a BLDC motor while maintaining the speed almost constant. In the next subsection, the case study is variable speed and constant load operation. The buck-boost chopper MOSFET switch voltage and current waveforms are shown in Figure $7 \mathrm{c}(\mathrm{i})$, and the proposed method is shown in Figure 7c(ii). The initial MOSFET voltage increased to $600 \mathrm{~V}$ initially and is then set to almost $370 \mathrm{~V}$, and slowly, the voltage is decreasing. The current also is high with about $+200 \mathrm{~V}$ and $-300 \mathrm{~V}$ under lighter load, and slowly the stress on it is decreasing. The MOSFET voltage with YSC is 
$330 \mathrm{~V}$ maximum, and the current is $400 \mathrm{~A}$ when motor is at start. Here, the current waveform is also DC and is increasing with an increase in the load. The stress current is maximum with 200A under heavy loaded condition and increasing for few milliseconds to $300 \mathrm{~A}$ to meet the load demand. Hence, the voltage and current stress under steadystate, transient, and at the starting is also lesser with the present method.

The duty cycle with the proposed method is shown in Figure $7 \mathrm{~d}$. To meet the starting current and load values, the switching is on for more time, and hence, the duty is 0.5 initially. When the speed adjusted and torque stabilized with its reference value, the duty ratio decreased to a small value. Once the load is again increasing, the duty cycle is increasing to meet the load torque demand. If there is a large rating, the capacitor of two times will reduce the duty cycle by one-third times the present one. However, increasing the capacitor rating will add additional cost to the system.

\subsection{Case B: Constant Torque and Variable Speed Control of BLDC Motor}

In the earlier case, constant speed variable torque is discussed; now, variable speed and constant torque will be considered. A half load of $30 \mathrm{~N}-\mathrm{m}$ is fixed, and speed reference is changed from 1000 to 1750 and $2500 \mathrm{rpm}$ at 0.075 and $0.15 \mathrm{~s}$, respectively. The machine parameters and others remained the same as those in the earlier case. The starting current with ZSC is $50 \mathrm{~A}$, and YSC is $62 \mathrm{~A}$, and this initial current is settled once the motor reaches steady-state reference value. It can be observed with the conventional method that, at low load torque and low speed, the armature current distorted with spikes and notches as shown in Figure 8a. But with the YSC as in Figure 8b, the current is trapezoidal, and amplitude is almost constant, and few negligible surges in the current are observed when the speed changes from one value to the other. In both cases, the frequency of the current waveform is increasing as speed is increasing. The back-emf is almost trapezoidal with both technique and this voltage increasing with the increase in the rotor speed.

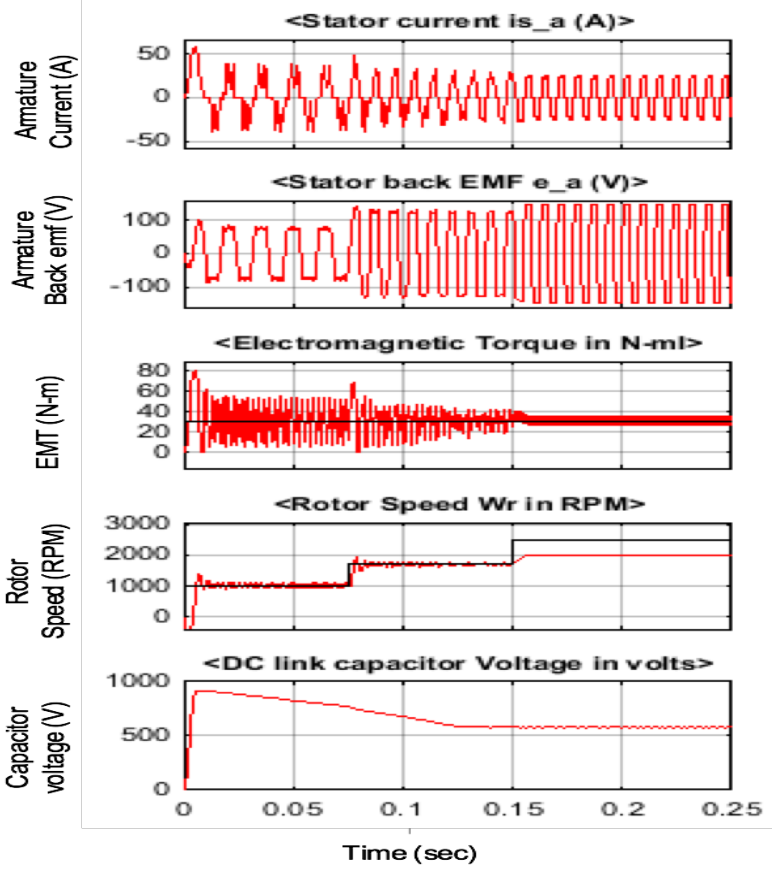

Figure 8a. BLDC motor parameters and DC link capacitor voltage with ZSC. 


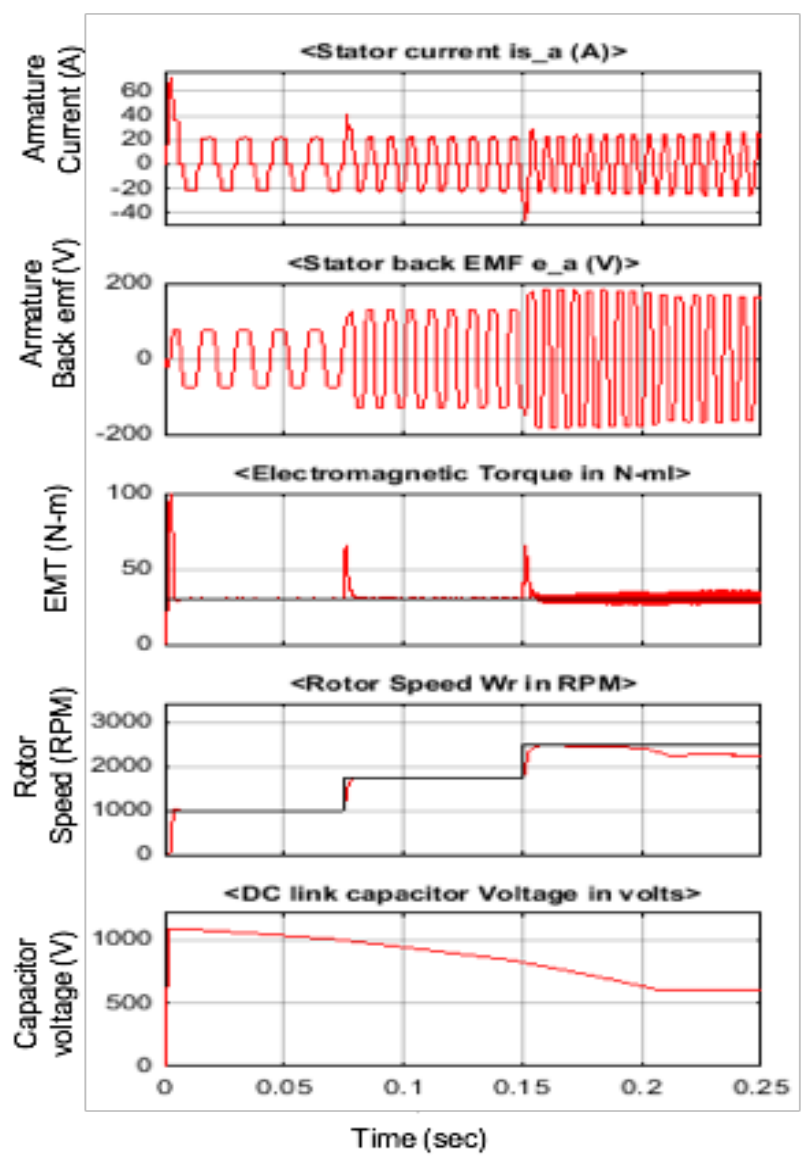

Figure 8b. YSC under constant torque and variable speed case study.

The ripple in the torque is high with ZSC and varies from 0 to $50 \mathrm{~N}-\mathrm{m}$ when the speed is lesser at $1000 \mathrm{rpm}$. The distortions decreased with the increase in speed and are less as speed increased to a higher value. In the same way, the torque ripples are lesser at lower speed with YSC and are almost the same as reference and actual torque. But few surges are observed when the speed adjustment is done because the change in the PI controller input and output values as speed is changed. When the reference and actual speed are compared in both controllers, there are few overshoots, and controlled oscillations are observed when speed transient takes place for PI controller. But when the speed is increased to a higher value at $2500 \mathrm{rpm}$, the rotor cannot adjust to the desired speed and attained only $2000 \mathrm{rpm}$. When YSC with the proposed technique output is observed, the reference and actual speeds are almost the same for speeds up to $1750 \mathrm{rpm}$, but a deviation of about $250 \mathrm{rpm}$ is observed with YSC, which is comparatively lesser in deviation than that with the ZSC configuration. The DC capacitor value, which is chosen as some small value in this paper, deviated from lesser speed value to higher speed value in both cases. But this voltage is maintained constant for more time with the rapid change in the speed with YSC. If higher value of capacitor is chosen, the capacitor link voltage is maintained constant; hence, speed deviation can be curtailed for both the cases. However, the performance with the same parameters of the proposed YSC is better than that with a ZSC design based conventional technique (Xia, Kun, 2016). 


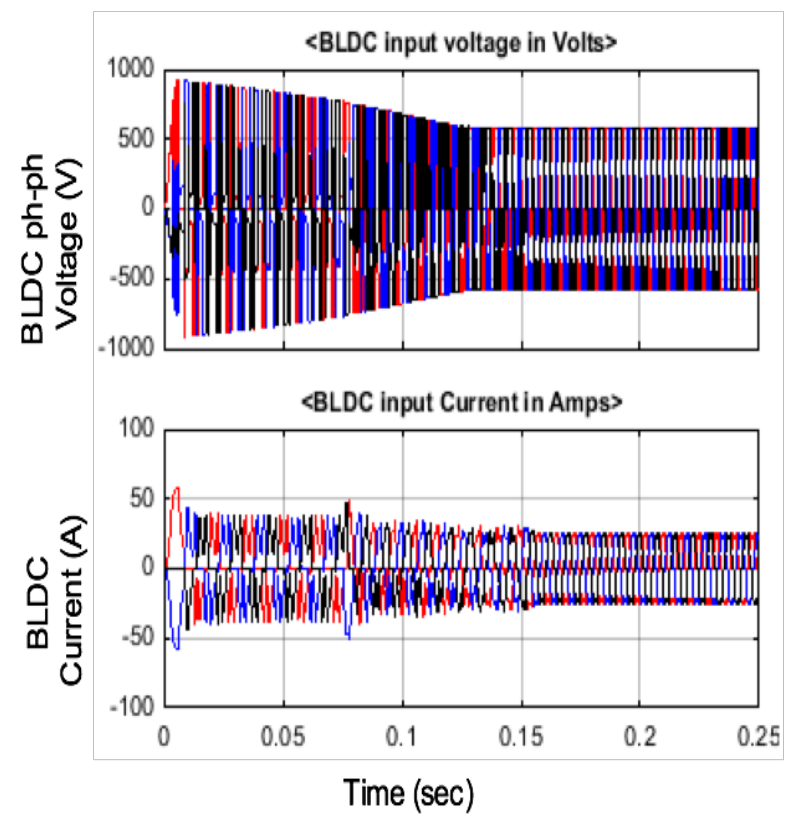

Figure 9a. BLDC motor inverter voltage and current with ZSC.

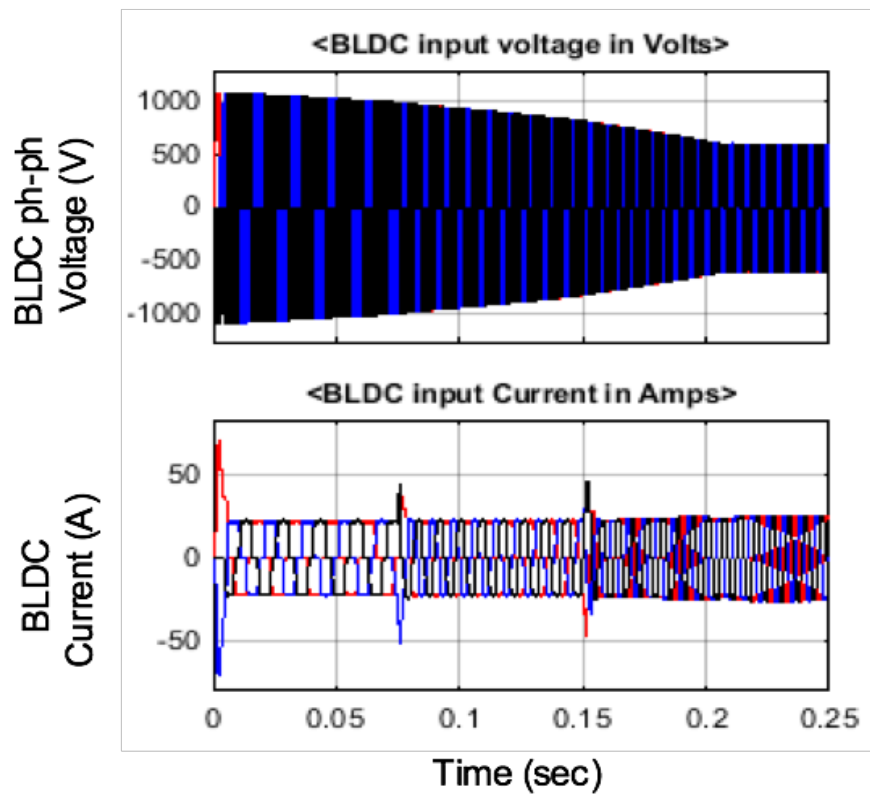

Figure 9b. YSC configuration.

The inverter voltage and current waveforms for conventional ZSC and YSC are shown in Figs. 9a and $9 \mathrm{~b}$. It can be observed that there are more distortions in the voltage and current waveforms at lower speeds than with higher speeds with conventional design (Xia, Kun, 2016), and the distortion in the voltage and current is lesser with YSC proposed. Frequency change in the waveform can be observed with both 
control schemes. The starting current is high with YSC. The input to PI controller is speed error, and the output is reference current. The ZSC topology based input and output waveforms are shown in Figure 9a, and with YSC, it is shown in Figure 9b. It is easily observed that, with the waveforms with ZSC design, there are few ripples in the speed error but are maintained at zero value till the speed is $1750 \mathrm{rpm}$. But when the speed further increased to a higher value of $2500 \mathrm{rpm}$, there is deviation in the speed to $500 \mathrm{rpm}$. However, there are no ripples in the YSC input or speed error value; hence, the desired speed is achieved. But surges are observed when speed change occurred at 0.075 and $0.15 \mathrm{~s}$. When the reference speed is adjusted to 2500, a deviation in the YSC is observed and is around $250 \mathrm{rpm}$.

The current reference value with PI is having large oscillations at lower speed and attained upper saturation value of 50A when the high speed of $2500 \mathrm{rpm}$ is demanded. With YSC, the current reference value or its output value changes considerably when the rotor speed demand changes. There are few spikes in the reference current value when speed transient occurred. Ripples in current are observed at very higher speed. When speed goes up to $2280 \mathrm{rpm}$, the speed deviation is very small with YSC, but beyond this speed, deviation in reference and actual speeds is observed. When compared with the work of Xia, Kun (2016) for BLDC torque ripple reduction, the performance of proposed technique for the BLDC motor is comparatively better with lesser ripples and effective speed and torque control mechanism. When the motor is started with heavy load, and if all the capacitors' voltages are very less or zero, the DC link chopper voltage is shown in Figure 10a, and the duty cycle of the switch Sd is shown in Figure 10b.

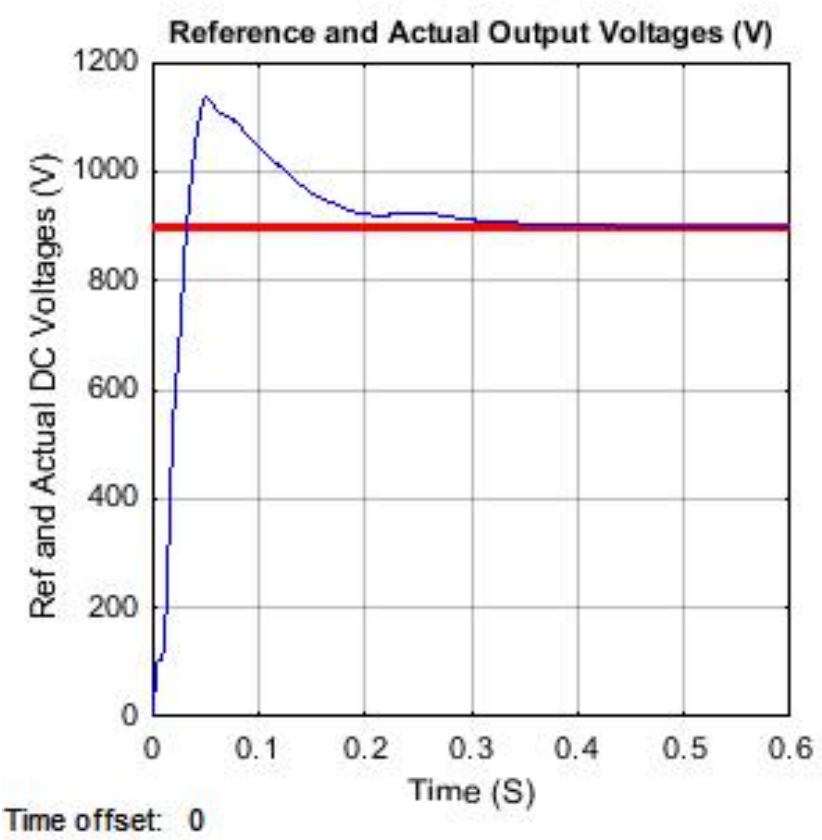

Figure 10a. DC link voltage across the capacitor. 


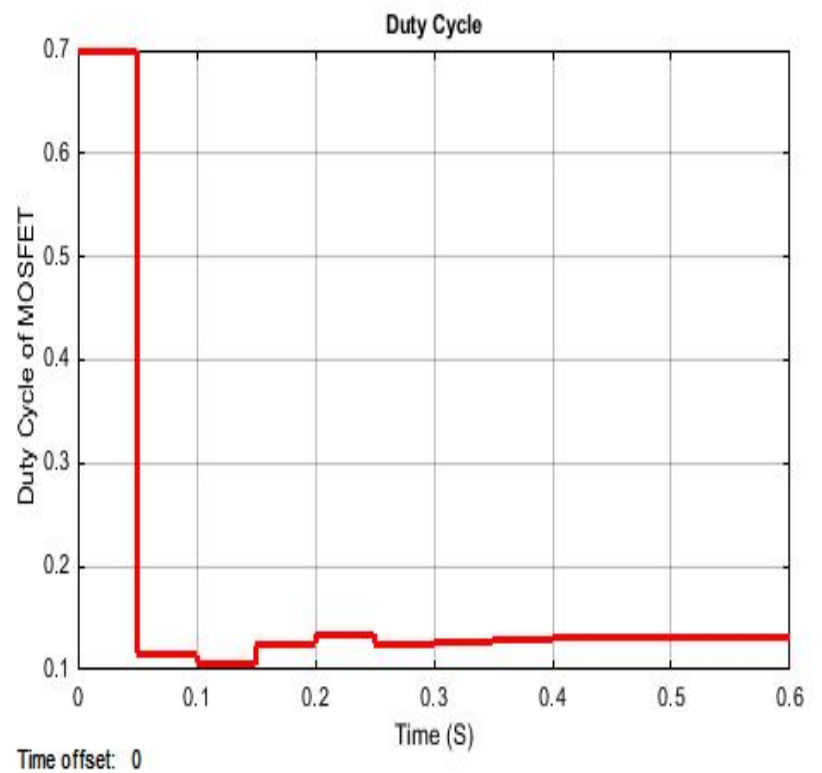

Figure 10b. Duty cycle of the YSC switch under heavy load condition.

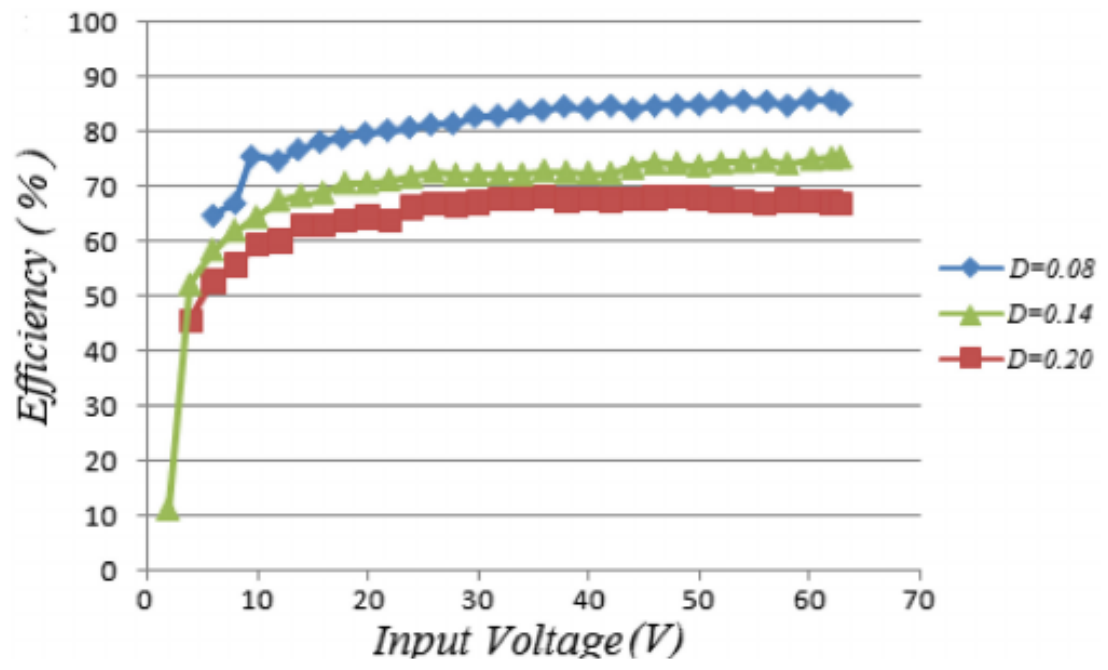

Figure 11. Efficiency vs input voltage characteristics of YSC under different duty cycles.

It can be observed from Figure 8a that when the capacitor voltage is low, the duty cycle is high, and when this voltage is increasing, the duty cycle is decreasing, respectively. When a steady DC voltage is obtained, the duty cycle will also remain almost constant. The efficiency vs input voltage under different duty cycles is shown in Figure 11. It can be observed that, with the increase in the duty cycle, the efficiency is decreasing. The YSC proposed topology will have very less switching stress and is better in performance and efficiency. 
In this case, both the torque and speed of the solar PV based BLDC motor are varying, and the parameters are observed for the analysis. The motor speed controller is controlled using a PI controller. The torque is changing from the initial value of $25 \mathrm{~N}-\mathrm{m}$ to $5 \mathrm{~N}-\mathrm{m}$ at $0.075 \mathrm{~s}$ and again increased to $25 \mathrm{~N}-\mathrm{m}$ at $0.15 \mathrm{~s}$, and finally, it reached $15 \mathrm{~N}-\mathrm{m}$ at $0.2 \mathrm{~s}$ as in Figure 12a. The rotor speed reference value is changed from the initial value of $1000 \mathrm{rap}$ to $2000 \mathrm{rpm}$ at $0.1 \mathrm{~s}$, and the BLDC motor and the DC link voltage actual waveforms are shown in Figure 12a. It can be observed that the starting torque is $45 \mathrm{~N}-\mathrm{m}$ till the rotor speed reaches its reference value of $1000 \mathrm{rpm}$. There are no ripples in the torque with the proposed method and topology than with a conventional six-switch topology.

When the torque is decreased at $0.075 \mathrm{~s}$ to $5 \mathrm{~N}-\mathrm{m}$, there is a small speed change, which can be neglected due to the rapid speed controlling action of the SMC. When the rotor speed in increased to twice its value, there is a small surge in the torque, and it immediately reaches its reference value. With the increase in the torque to rated value at rated speed, torque small ripples are observed, as well as a small deviation in the rotor speed from 2000 to $1900 \mathrm{rpm}$ due to large load torque application to the motor as shown in Figure 12a. Once the load is decreased by $10 \mathrm{~N}-\mathrm{m}$ to a value of $15 \mathrm{~N}-\mathrm{m}$, the torque ripples are decreased, and the rotor speed also reached its normal value. With the increase in the torque, the armature current is increasing in magnitude, and with the increase in the rotor speed, waveform frequency is also increasing, but surges are very less with the proposed scheme and topology. With the change in the load torque of the motor, the DC link capacitor voltage is also changing, respectively, to supply the desired voltage and current. As there is no chopper control action, the seventh switch only will actively control the buck and boost action for the inverter.
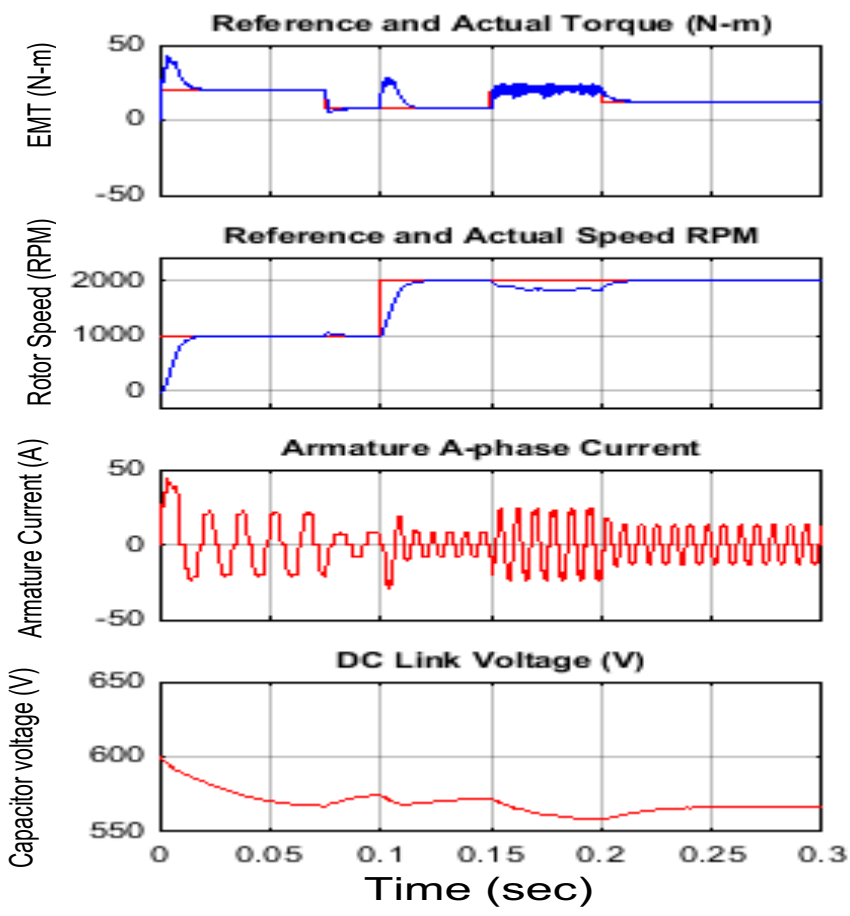

Figure 12a. BLDC motor parameters and DC link voltage with SMC. 


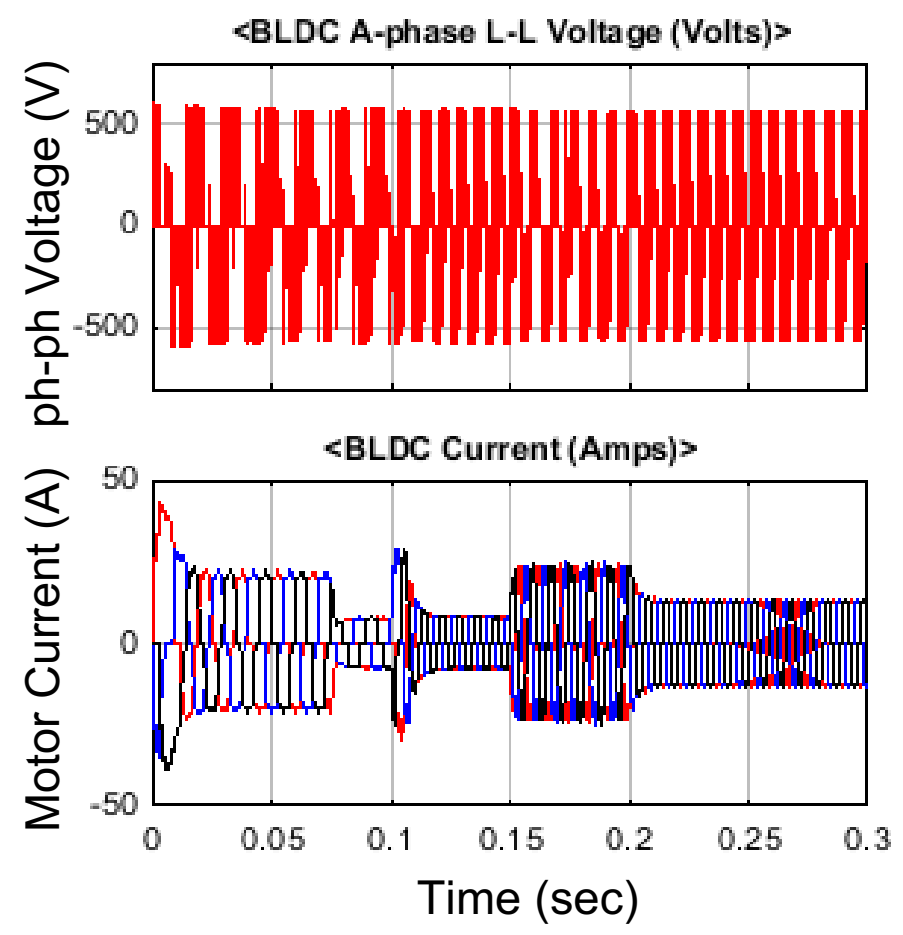

Figure 12b. BLDC motor input inverter voltage and current.

The BLDC motor voltage source inverter A-phase voltage and three-phase current waveforms are shown in Figure 12b. The voltage magnitude is almost constant but is square wave in shape, and the current magnitude is changing in all the three phases equally in magnitude and frequency with respective change in the torque and the rotor speed. The current waveform is trapezoidal, and there are no surges when the torque or speed is changing. The starting current is also high, but the voltage is constant with the proposed control scheme.

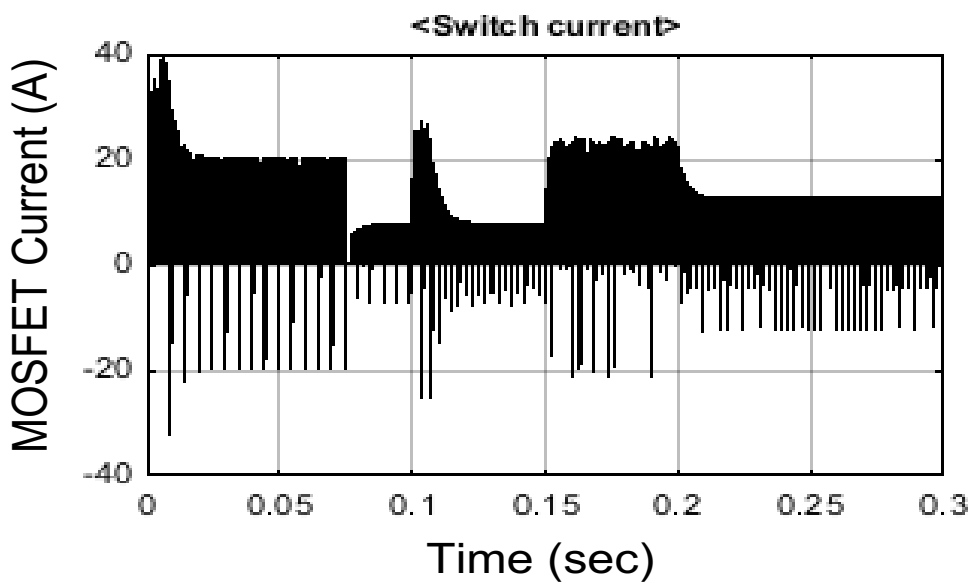

Figure 13a. IGBT current through the MOSFET Sd switch. 


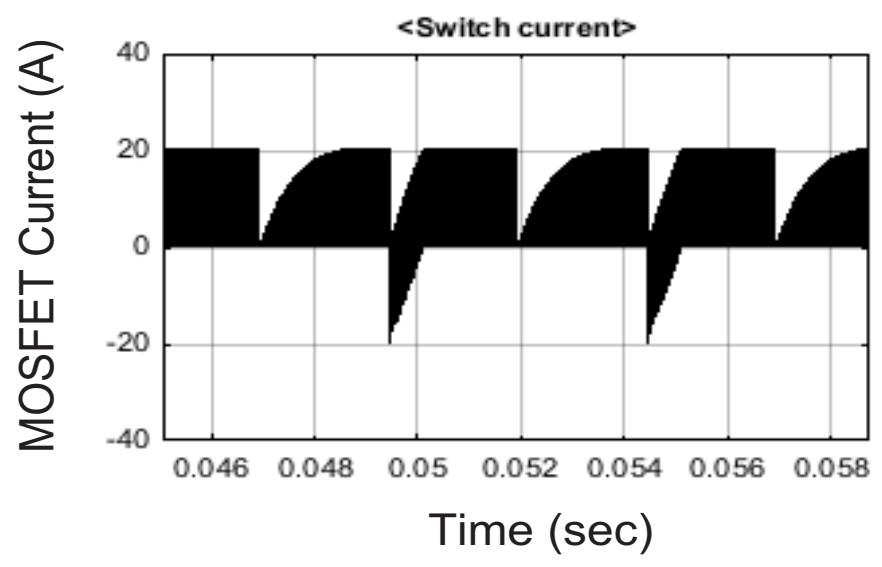

Figure 13b. Zoom waveform of IGBT current for Figure 13a.

The seventh switch location is shown in Figure 1e, the current through this switch is shown in Figure 13a, and the zoom of the waveform is shown in Figure 9b. The switching current is high when the motor requires high starting current, and this current is very small when there is a decrease in the load torque at $0.075 \mathrm{~s}$. When there is a speed change, the current also is increased till the reference speed is reached. It can also be seen in Figure 13b that the current is almost constant, and the switching action is very optimal when YSC topology is used with the proposed control scheme.

Harmonic amplitude in percent of the fundamental component

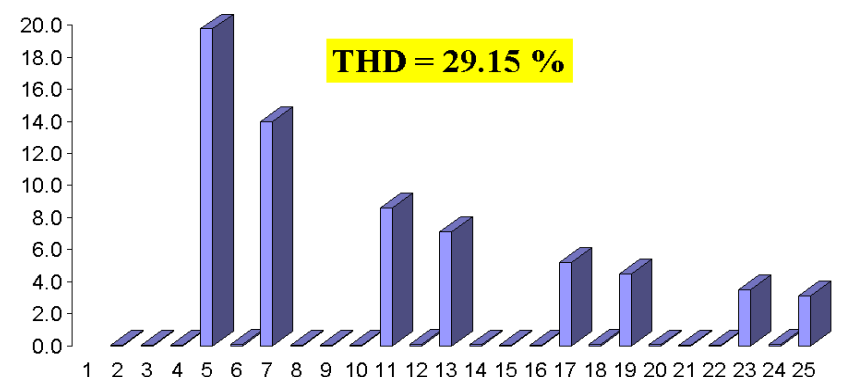

Figure 14(a). BLDC voltage THD values with ZSI.

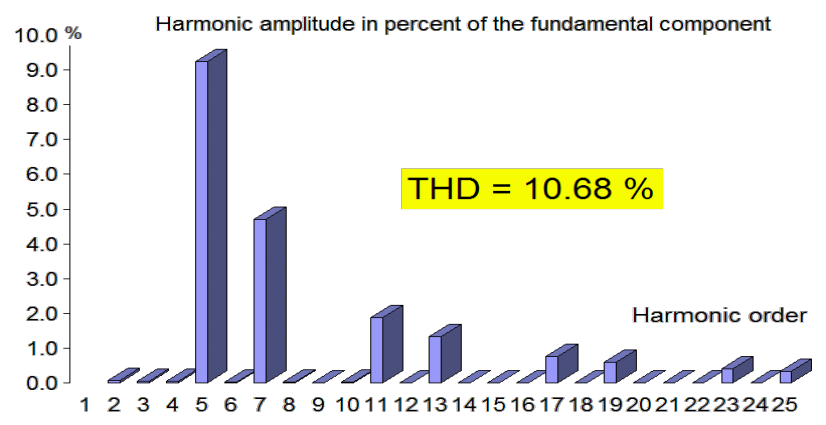

Figure 14(b). PI controller using Y source inverter topology. 


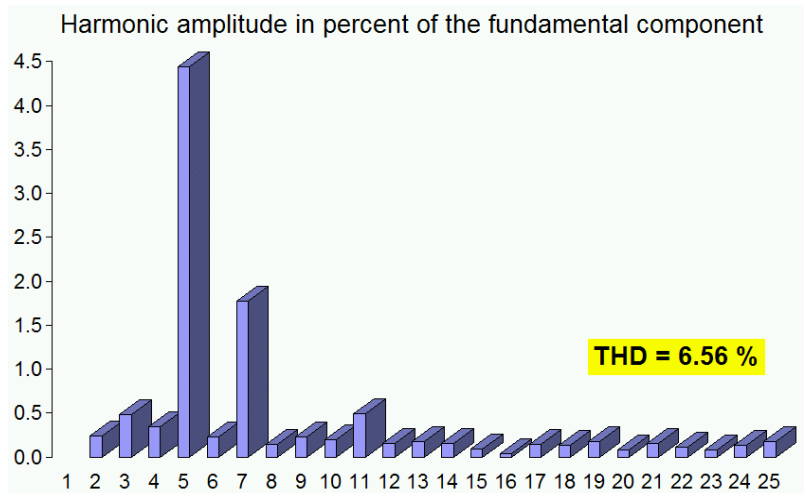

Figure 15(a). BLDC current THD values with ZSI.

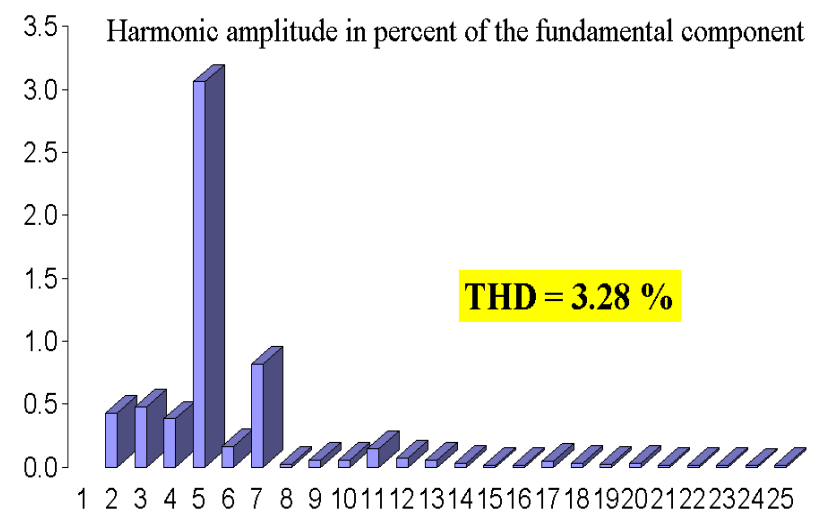

Figure15(b). PI controller using Y source inverter topology.

The current is having some harmonic components, but the current is in-phase with the same phase voltage. The THD values of current and voltage are shown in Figs. 14(a) and 14(b) using ZSI and YSI topologies. The current THD is $10.68 \%$, and the voltage is $29.15 \%$ with a harmonic order of $5,7,11,13,17$, and 19 significant. At full load, the harmonic content of the output current is minimized by the influence of the machine stator equivalent inductance and resistance, which are $\mathrm{L}_{-} \mathrm{F} 1=3 \mathrm{mH}$ and $\mathrm{R}_{-} \mathrm{s} 1=0.432 \Omega$, respectively. Unfortunately, this effect is not so noticeable when the available wind decreases, and therefore, the maximal output power decreases, and the THD increases. The amplitude of the $5^{\text {th }}$ current harmonic is $9.2 \%$ of the fundamental, which is greater than the $4 \%$ allowed by IEEE 519 standard. Of course, the IEEE 519 standard is not applicable to this situation, but it is a guideline.

The THD presented with the YSI is lower than 3.5\%, and the low amplitude of the 5th harmonic under 3.5\% reveals the suitability of this topology to harmonic mitigation as shown in Figure 15(a). An effective improvement in the voltage THD was obtained, and the results are shown in Figure 15(b). These good results were obtained for a constant duty cycle below $50 \%$. The main drawback of this ZSI topology is the high output voltage $1 \mathrm{kV}$, in as much the line-to-line BLDC RMS output voltage has increased to $220 \mathrm{~V}$ at full load, and the BLDC line current has decreased once the output power was kept constant at $2 \mathrm{~kW}$. A comparison of the conventional inverter without chopper, with ZSI, and with proposed YSI showing different losses and efficiency is denoted in Table 1. Compared to the combination, the proposed YSI topology is better in terms of THD, PFC, and also efficiency than with ZSI topology or without a chopper based direct inverter. 
Table 1. BLDC core, copper, friction, and windage losses in (W) and efficiency in (\%).

\begin{tabular}{|c|c|c|c|c|c|}
\hline Topology & $\begin{array}{c}\text { Copper } \\
\text { Losses }\end{array}$ & Core Losses & $\begin{array}{c}\text { Friction \& } \\
\text { Windage } \\
\text { losses }\end{array}$ & $\begin{array}{c}\text { Cumulative } \\
\text { losses }\end{array}$ & $\begin{array}{c}\text { Overall effi- } \\
\text { ciency of } \\
\text { the drive }\end{array}$ \\
\hline Rated & 1701.15 & 219.40 & 120 & 2040.55 & 90.74 \\
\hline $\begin{array}{c}\text { Conventional inverter } \\
\text { without chopper }\end{array}$ & 2318.93 & 180.82 & 120 & 2619.75 & 88.42 \\
\hline $\begin{array}{c}\text { Z-Source Inverter (ZSI) } \\
\text { Y-Source Inverter (YSI) }\end{array}$ & 1724.73 & 251.32 & 120 & 2096.05 & 90.51 \\
\hline
\end{tabular}

\section{CONCLUSION}

The Y-source converter (YSC) based DC-to-DC chopper configuration with conventional six-switch inverter topology is considered in this paper to observe the performance of brushless DC (BLDC) motor. In this paper, the position sensor and speed are measured in a conventional way using a hysteresis sensor. But, YSC topology and the inverter control scheme are different and are designed to improve the BLDC motor performance under load and speed changes with better performance as major objective. The torque ripple reduction is a secondary objective of this work. The technique improved the speed and torque control and also effectively curtailed the torque ripples and back-emf waveform when compared to conventional vector control scheme with ZSC. The proposed technique is helpful for high speed up to $2500 \mathrm{rpm}$ and with large motor load torque about $60 \mathrm{~N}-\mathrm{m}$. The speed and torque surges and ripples are very less. With small rated DC link capacitor value, the speed and torque control with better waveforms are observed. The inverter voltage and current waveform are trapezoidal with lesser distortions. This technique is applicable to water pump system and automotive system where load fluctuations and speed variations are more. As fluctuations in speed and torque are also less, it can be used for emergency systems and advanced control systems like robotic arms and medical applications. Therefore, from all the above, the overall performance of BLDC motor is improved with the proposed YSC topology and the inverter control scheme. The future scope of the work is to maintain the speed deviation to as low as possible even at higher load torque or rotor speed with limited rating capacitor value.

\section{APPENDIX}

The BLDC parameters: $\mathrm{Rs}=1.8750 \Omega, \mathrm{Ls}=8.5 \mathrm{mH}$, flux linkage $=0.175$, back-emf flat area is $120^{\circ}$, moment of inertia $(J)=0.8 \mathrm{mkg}-\mathrm{m}^{2}$, friction coefficient $(\mathrm{F})=1 \mathrm{mN}-\mathrm{m}-\mathrm{s}$, pole pairs $(\rho)=4 . \mathrm{L} 1=1.5 \mathrm{mH}, \mathrm{L} 2=1.25 \mathrm{mH}, \mathrm{C} 1=970 \mu \mathrm{F}$, $\mathrm{C} 2=370 \mu \mathrm{F}, \mathrm{C} 3=470 \mu \mathrm{F}, \mathrm{C} 4$ and $\mathrm{C} 5$ are $940 \mu \mathrm{F}$. The windings are having turns ratio of 1:5:3. 


\section{REFERENCES}

Ahmed, Mahrous, Basem Alamri, Mohamed Metwaly, Mosleh Alharthi, Nagy Elkalashy, Farhan Salem, Saad Mekhilef, Mohamed Orabi, and Sherif Ghoneim. (2021) "Multi-Level Inverter Integration for Low Voltages Ride Through for Controlling Renewable Wind Energy Conversion Systems." Journal of Engineering Research 9, no. 2.

Alharbi, Ahmed Awadh, Feraih Sh Aenazey, Saud A. Binjuwair, Ibrahim A. Alshunaifi, Abdullah M. Alkhedair, Abdullah J. Alabduly, Mohammed S. Almurat, and Miqad S. Albishi. (2020) "Reducing NOx emissions by adding hydrogen-rich synthesis gas generated by a plasma-assisted fuel reformer using Saudi Arabian market gasoline and ethanol for different air/fuel mixtures." Journal of Engineering Research 8 , no. 1 .

Al-Othman, Abdulrahman K., Nabil Nabil A. Ahmed, M. E. AlSharidah, K. M. El-Naggar, and Bader N. Alajmi. (2016) "Experimental implementation of PEM fuel cell powered DC motor for vehicle applications." Journal of Engineering Research 4, no. 3.

Alouane, Asma, Asma Ben Rhouma, and Adel Khedher, (2018). "FPGA Implementation of a New DTC Strategy Dedicated to Delta Inverter-Fed BLDC Motor Drives." Electric Power Components and Systems 46, no. 6: 688-700.

Banu Rekha, B., B. Somasundaram, L. Ashok Kumar, and Pruthviraj Balekai. (2018) "A Technical Review on Advantages of Using EC BLDC Fans in Factory and Commercial Buildings."Energy Engineering 115, no. 3: 57-74.

Carey, Kellen D., Nathan Zimmerman, and Cristinel Ababei. (2018) "Hybrid field oriented and direct torque control for sensorless BLDC motors used in aerial drones." IET Power Electronics 12, no. 3: 438-449.

Çelikel, Reşat, and Ömür Aydoğmuş. (2019) "A torque ripple minimization method for brushless dc motor in high speed applications." Journal of Engineering Research 7, no. 3.

Cetin, Sevilay. (2014) "Optimization of a self-driven current-doubler phase shifted full bridge DC-DC converter with integrated magnetic." Journal of Engineering Research 2, no. 4, 1-19.

Chen, Shaohua, Gang Liu, and Lianqing Zhu. (2017) "Sensorless control strategy of a 315 kW high-speed BLDC motor based on a speed-independent flux linkage function." IEEE Transactions on Industrial Electronics 64, no. 11: 8607-8617.

De Castro, Allan Gregori, William Cesar Andrade Pereira, Thales Eugenio Portes de Almeida, Carlos Matheus Rodrigues de Oliveira, José Roberto Boffino de Almeida Monteiro, and Azauri Albano de Oliveira. (2018) "Improved finite control-set model-based direct power control of BLDC motor with reduced torque ripple." IEEE Transactions on Industry Applications 54, no. 5: 4476-4484.

El-Samahy, Adel A., and Mohamed A. Shamseldin. (2018) "Brushless DC motor tracking control using selftuning fuzzy PID control and model reference adaptive control." Ain Shams Engineering Journal 9, no. 3: 341-352.

Gujjar, Meghana N., and Pradeep Kumar. (2017) "Comparative analysis of field oriented control of BLDC motor using SPWM and SVPWM techniques." In 2017 2nd IEEE International Conference on Recent Trends in Electronics, Information \& Communication Technology (RTEICT), pp. 924-929. IEEE,

Guo, Xiaoqiang. (2016) "Experimental verification of a new positive feedback islanding detection method for grid-connected inverter." Journal of Engineering Research 4, no. 3.

Jagiela, Mariusz, Tomasz Garbiec, Janusz Gwozdz, and Janusz Kolodziej. (2015) "Fast steady-state fieldcircuit model for SMPM-BLDC motors driven from 120 and 180 quasi-square wave inverters." IEEE Transactions on Magnetics 52, no. 3: 1-4. 
Jianwen Shao, D. Nolan, M. Teissier and D. Swanson, (2003)"A novel microcontroller-based sensorless brushless DC (BLDC) motor drive for automotive fuel pumps," in IEEE Transactions on Industry Applications, vol. 39, no. 6, pp. 1734-1740.

J. Feng, K. Liu and Q. Wang, (2018)"Scheme based on buck-converter with three-phase H-bridge combinations for high-speed BLDC motors in aerospace applications," in IET Electric Power Applications, vol. 12, no. 3, pp. 405-414, 3 .

J. Shao, (2006) "An Improved Microcontroller-Based Sensorless Brushless DC (BLDC) Motor Drive for Automotive Applications," in IEEE Transactions on Industry Applications, vol. 42, no. 5, pp. 1216-1221.

Kommula, Bapayya Naidu, and Venkata Reddy Kota. (2018) "Direct instantaneous torque control of Brushless DC motor using firefly Algorithm based fractional order PID controller." Journal of King Saud University-Engineering Sciences .

Krishnan, TV Dhaneesh, C. M. C. Krishnan, and K. Panduranga Vittal. (2017) "Design of robust H-infinity speed controller for high performance BLDC servo drive." In 2017 International Conference on Smart grids, Power and Advanced Control Engineering (ICSPACE), pp. 37-42. IEEE,

Lad, Chetan K., and Rajagopalan Chudamani. (2018) "Simple overlap angle control strategy for commutation torque ripple minimisation in BLDC motor drive." IET Electric Power Applications 12, no. 6 : 797807.

Li, Xinmin, Changliang Xia, Yanfei Cao, Wei Chen, and Tingna Shi. (2016) "Commutation torque ripple reduction strategy of Z-source inverter fed brushless DC motor." IEEE Transactions on Power Electronics 31, no. 11: 7677-7690.

López, Manuel García, Pedro Ponce, Luis Arturo Soriano, Arturo Molina, and Jaime José Rodríguez Rivas. (2019) "A Novel Fuzzy-PSO Controller for Increasing the Lifetime in Power Electronics Stage for Brushless DC Drives." IEEE Access 7: 47841-47855.

Lu, Youliang, and Xiong Xie. (2018) "Sliding Mode Observer of BLDC Motor Drive Under DTC Scheme with Hall Signals." InProceedings of the 2018 International Conference on Robotics, Control and Automation Engineering, pp. 60-64. ACM.

Murali, S. Bala, and P. Mallikarjuna Rao. (2018) "Adaptive sliding mode control of BLDC motor using cuckoo search algorithm." In 2018 2nd International Conference on Inventive Systems and Control (ICISC), pp. 989-993. IEEE.

Özçelik, Mehmet Ali. (2015) "Improving the performance of MPPT in photovoltaic systems by modified perturb and observe algorithm." Journal of Engineering Research 3, no. 3.

Potnuru, Devendra, K. Alice Mary, and Ch Sai Babu. 2019 "Experimental implementation of Flower Pollination Algorithm for speed controller of a BLDC motor." Ain Shams Engineering Journal .

Premkumar, K., and B. V. Manikandan. (2015) "GA-PSO optimized online ANFIS based speed controller for Brushless DC motor."Journal of Intelligent \& Fuzzy Systems 28, no. 6: 2839-2850.

Premkumar, K., and B. V. Manikandan. (2018) "Stability and Performance Analysis of ANFIS Tuned PID Based Speed Controller for Brushless DC Motor." Current Signal Transduction Therapy 13, no. 1: 19-30.

Premkumar, K., and B. V. Manikandan. (2015) "Speed control of Brushless DC motor using bat algorithm optimized Adaptive Neuro-Fuzzy Inference System." Applied Soft Computing 32: 403-419.

Qamar, Nezar Abou, and Constantine J. Hatziadoniu. "Cancellation of selected stator harmonics in BLDC by using an adaptive feed forward controller." Electric Power Systems Research 154 (2018): 88-94.

Ransara, HK Samitha, and Udaya K. Madawala. (2015), "A torque ripple compensation technique for a lowcost brushless DC motor drive." IEEE Transactions on Industrial Electronics 62, no. 10: 6171-6182. 
R. Kumar and B. Singh, (2016), "BLDC Motor-Driven Solar PV Array-Fed Water Pumping System Employing Zeta Converter," in IEEE Transactions on Industry Applications, vol. 52, no. 3, pp. 2315-2322.

Sekhar, GT Chandra, Budi Srinivasa Rao, and Krishna Mohan Tatikonda. "SVPWM-Based DTC Controller for Brushless DC Motor." In Computational Intelligence in Data Mining, pp. 759-769. Springer, Singapore, 2017.

S. P. Nikam, V. Rallabandi and B. G. Fernandes, (2012)"A High-Torque-Density Permanent-Magnet Free Motor for in-Wheel Electric Vehicle Application," in IEEE Transactions on Industry Applications, vol. 48, no. 6, pp. 2287-2295.

Sumega, Martin, Šimon Zoššák, Patrik Varecha, and Pavol Rafajdus. "Sources of torque ripple and their influence in BLDC motor drives." Transportation Research Procedia 40 (2019): 519-526.

Soumi, A., and A. Prince. (2018)"A Novel Approach of Sensorless Control of BLDC Motor with Z-Source Inverter." Journal of Power Electronics \& Power Systems 8, no. 3: 9-16.

Siwakoti, Yam P., Frede Blaabjerg, and Poh Chiang Loh. (2015), "Quasi-Y-source boost DC-DC converter." IEEE Transactions on Power Electronics 30, no. 12: 6514-6519.

Suryoatmojo, H., A. P. Nandiwardhana, N. R. Arsya, S. Anam, H. P. Putra, R. Mardiyanto, and M. Ashari. (2016), "Comparisons of Cuk, SEPIC and Zeta converter performance for harmonics mitigation and PFC in BLDC speed control." In2016 International Seminar on Intelligent Technology and Its Applications (ISITIA), pp. 681-686. IEEE,.

Toliyat, Hamid A., and Gerald B. Kliman, eds. (2017), Handbook of electric motors. Vol. 120. CRC press, 2018.

Valle, Rodolfo L., Pedro M. De Almeida, Andre A. Ferreira, and Pedro G. Barbosa. "Unipolar PWM predictive current-mode control of a variable-speed low inductance BLDC motor drive." IET Electric Power Applications 11, no. 5: 688-696.

Viswanathan, Vaiyapuri, and Jeevananthan Seenithangom. (2017) "Commutation torque ripple reduction in the BLDC motor using modified SEPIC and three-level NPC inverter." IEEE Transactions on Power Electronics 33, no. 1: 535-546.

W. Lee, J. H. Kim, W. Choi and B. Sarlioglu, (2018)"Torque Ripple Minimization Control Technique of High-Speed Single-Phase Brushless DC Motor for Electric Turbocharger," in IEEE Transactions on Vehicular Technology, vol. 67, no. 11, pp. 10357-10365.

Wang, Yijie, Wenli Jing, Yuping Qiu, Yuanyuan Wang, Xiangyuan Deng, Ke Hua, Benran Hu, and Dianguo Xu. (2018)"A family of Y-source DC/DC converter based on switched inductor." IEEE Transactions on Industry Applications 55, no. 2: 1587-1597.

Xia, Kun, Jing Lu, Chao Bi, Yuan Tan, and Bin Dong. (2016) "Dynamic commutation torque-ripple reduction for brushless DC motor based on quasi-Z-source net." IET Electric Power Applications 10, no. 9: 819826. 